Review Article

\title{
Prevalence and Traits of Mobile Colistin Resistance Gene Harbouring Isolates from Different Ecosystems in Africa
}

\author{
Madubuike Umunna Anyanwu ${ }^{1},{ }^{1}$ Charles Odilichukwu R. Okpala $\mathbb{D}^{2}$ \\ Kennedy Foinkfu Chah $\left(\mathbb{1},{ }^{1}\right.$ and Vincent Shodeinde Shoyinka $\mathbb{( I}^{1}$ \\ ${ }^{1}$ Department of Veterinary Pathology and Microbiology, University of Nigeria, Nsukka 400001, Nigeria \\ ${ }^{2}$ Department of Functional Food Products Development, Faculty of Biotechnology and Food Science, Wroclaw University of \\ Environmental and Life Sciences, Wroclaw, Poland
}

Correspondence should be addressed to Madubuike Umunna Anyanwu; madubuike.anyanwu@unn.edu.ng

Received 30 November 2020; Revised 5 January 2021; Accepted 13 January 2021; Published 23 January 2021

Academic Editor: Mohamed Salah Abbassi

Copyright (c) 2021 Madubuike Umunna Anyanwu et al. This is an open access article distributed under the Creative Commons Attribution License, which permits unrestricted use, distribution, and reproduction in any medium, provided the original work is properly cited.

\begin{abstract}
The mobile colistin resistance $(\mathrm{mcr})$ gene threatens the efficacy of colistin (COL), a last-line antibiotic used in treating deadly infections. For more than six decades, COL is used in livestock around the globe, including Africa. The use of critically important antimicrobial agents, like COL, is largely unregulated in Africa, and many other factors militate against effective antimicrobial stewardship in the continent. Currently, ten $m c r$ genes ( $m c r-1$ to $m c r-10)$ have been described. In Africa, $m c r-1$, $m c r-2, m c r-3, m c r-5, m c r-8$, and $m c r-9$ have been detected in isolates from humans, animals, foods of animal origin, and the environment. These genes are harboured by Escherichia coli, Klebsiella, Salmonella, Citrobacter, Enterobacter, Pseudomonas, Aeromonas, Alcaligenes, and Acinetobacter baumannii isolates. Different conjugative and nonconjugative plasmids form the backbone for $m c r$ in these isolates; however, $m c r-1$ and $m c r-3$ have also been integrated into the chromosome of some African strains. Insertion sequences (ISs) (especially ISApl1), either located upstream or downstream of $m c r$, class 1 integrons, and transposons, are drivers of $m c r$ in Africa. Genes coding multi/extensive drug resistance and virulence are colocated with $m c r$ on plasmids in African strains. Transmission of $m c r$ to/among African strains is nonclonal. Contact with $m c r$-habouring reservoirs, the consumption of contaminated foods of animal/plant origin or fluid, animal-/plant-based food trade and travel serve as exportation, importation, and transmission routes of $\mathrm{mcr}$ gene-containing bacteria in Africa. Herein, the current status of plasmid-mediated COL resistance in humans, food-producing animals, foods of animal origin, and environment in Africa is discussed.
\end{abstract}

\section{Introduction}

Colistin (COL) is one of the few last-line antibiotics used in treating deadly infections caused by multidrug-resistant (MDR) and extensively drug-resistant (XDR) Gramnegative bacilli (GNB). The unrestricted use of antibiotics in human medicine, especially in form of self-medication that is predominant in low and middle-income countries, is a major cause of development of antimicrobial drug resistance [1]. The use of COL in humans was largely abandoned in the 1970s due to its neurotoxic and nephrotoxic effects alongside to the discovery and approval of new and effective antibiotics [2], but COL has been used in livestock for more than six decades in most countries in the world, including Africa [3-5]. In GNB, including Enterobacterales and nonfermenting GNB (such as Pseudomonas, Acinetobacter, and Aeromonas), the major mechanism of COL resistance is by the addition of 4-amino-4-deoxy-L-arabinose (L-Ara4N) and phosphoethanolamine ( $\mathrm{pEtN}$ ) to the lipid A, a moiety of lipopolysaccharide (LPS), which decreases the electrostatic interaction between COL and LPS [6, 7]. Before 2015, mutation in chromosomal genes, such as $p m r A B$, $p h o P Q, m g r B$, and $c c r B$, were the known mechanisms of COL resistance. Uncommonly used in humans due to the availability of effective antibiotics, and considering the chromosomal genes would only transfer vertically to the progenies of a specific 
bacterial clones, there was a low interest in pursuing the COL resistance concept [8]. However, in the early 2000s, clinicians were forced to use COL in treating deadly infections caused by rapidly evolving and spreading MDR and XDR organisms $[5,9,10]$. Unfortunately, in late 2015 , it was discovered that the clinical usefulness of COL is threatened by a plasmidborne transmissible COL resistance determinant, mobile colistin resistance $(m c r-1)$ [11]. Plasmids are highly mobile circular/linear extrachromosomal segments of DNA that can acquire insertion sequences, integrons, and transposons to disseminate resistance genes by horizontal gene transfer (HGT) [12].

There are ten $m c r$ genes ( $m c r-1$ to $m c r-10)$ with many variants that have been detected in isolates from humans, animals, and environment across over 60 countries in 6 of the 7 continents except Antarctica [3,5]. These genes encode MCR, which are transmembrane phosphoethanolamine (pEtN) transferases (proteins) conferring resistance to COL by adding a pEtN moiety to the lipid A of LPS in the outer membrane of GNB [13].

One Health paradigm involves surveillance of AMR resistance in humans, animals, and the environment [1416]. Potentially pathogenic and resistant organisms emanating from either of these ecosystems move with ease to another [17]. The release of antimicrobials, antimicrobialresistant bacteria, and ARGs by humans and animals (by ejection or by anthropogenic activities) into the environment results in the contamination of soil, aquatic systems, plants, and wildlife has serious ramifications on public health [17, 18]. Crops/plants (particularly vegetables and fruits) contaminated with COL-resistant organisms when consumed raw or undercooked by humans/animals pose a serious risk to the consumer's health [19]. Contaminated surface waters are considerable reservoirs for the transmission of COLresistant organisms to the food chain in Africa because plants are irrigated and foods are processed with these waters.

COL resistance genes emerging from Africa, as any other continent, can be disseminated through international food (animal- and plant-based) trade and travel [20]. Thus, understanding the epidemiology, phenotypic, and genotypic characteristics of $m c r$-carrying isolates, the genetic context of $m c r$ in the isolates, and population structure and mechanism of acquisition of $\mathrm{mcr}$ genes by organisms in Africa creates the needed impetus to tackle the problem to reduce the risk to public health [19]. Therefore, this current review articulates the findings of studies on plasmid-mediated COL resistance among isolates from different food-producing animals, foods of animal origin, humans, and environment in Africa.

\section{Plasmid-Mediated Colistin Resistance among Isolates from Food-Producing Animals, Foods of Animal Origin, Environment, and Humans in Africa}

2.1. Food-Producing Animals. COL has been used in the livestock sector in Africa for many decades. Thus, bacteria colonizing domesticated animals in Africa have developed resistance to COL. Twenty publications investigated plasmid-mediated COL resistance in 1096 faecal (rectal/cloacal) isolates from food-producing animals in Africa [21-40]. The studies reported $\mathrm{mcr}$-1 gene in 199 isolates (197 E. coli and one each for Citrobacter freundii and Alcaligenes faecalis), $m c r-5$ gene in one E. coli, and $m c r-8$ gene in one each for E. coli and K. pneumoniae. Two of the studies probed $m c r-1$ directly in faecal samples $[22,33]$.

2.1.1. Poultry. The poultry sector in Africa has been reported as a reservoir for plasmid-mediated COL resistance [22-24, 26-29, 31-34, 37-39]. In Northern Africa, $m c r-1$ was detected in 106/110 (96.4\%), 16/109 (14.7\%), 9/113 (8\%), and $3 / 12(25 \%)$ E. coli isolates from chickens/samples of chicken meat in Tunisia [24, 32, 34, 37, 39], Algeria [22, 26, 28, 33], Egypt [29, 31], and Morocco [38], respectively. This indicates that $m c r-1$ is widely circulating more among E. coli strains in the Tunisian poultry sector than in the other countries. It means that COL/other antimicrobial agents might be used more frequently in Tunisian livestock sector than in other Northern African countries. The $m c r-1$-positive isolates from the Egyptian poultry sector were isolated during 2010-2016, and they also contained virulence-associated genes (VAGs) and 18 additional resistance genes (including extended spectrum $\beta$-lactamase (ESBL) and plasmidic Ampicillinase $\mathrm{C}$ (pAmpC) genes) belonging to six antimicrobial families $[29,31]$ (Table 1), suggesting that organisms producing MCR-1 and ESBL/pAmpC have been present in Africa since at least 2010. Isolates from the Tunisian poultry sector carried $m c r-1$ on diverse plasmids (IncHI2, IncI2, $242 \mathrm{~kb}$ IncP, and IncFIB) $[32,34,39]$, and they also possessed class 1 integrons and 21 antibiotic resistance genes (including ESBL and pAmpC genes) belonging to four antimicrobial families [24, 32, 34, 37, 39] while transposon ISApl1 was upstream of $m c r-1$ which was carried on IncHI2 plasmid in isolates from the Algerian poultry sector [28]. These findings suggest that diverse mobile genetic elements (MGEs) (plasmids, integrons, and transposons) facilitate the acquisition and transfer of $m c r-1$ in North Africa. It also suggested that the poultry sector in the region is a reservoir of cocktails of multiresistance genes, and that the localization of other resistance genes on $\mathrm{mcr}$-1-plasmid favors the selection of COLresistant strains under the selective pressure imposed by other antibiotics.

Some of the $m c r$-1-positive isolates from the Tunisian poultry sector were from poultry farms that imported chickens from France or derived their flocks from French chicks [24], suggesting that food animal trade is a route for the importation of plasmid-mediated COL resistance into Africa. However, the animals could also have been contaminated after their arrival or subsequent rearing stages in Tunisia [20]. The mcr-1-positive isolates from the Tunisian poultry sector were extensively diverse, belonging to phylogroups A, B1, B2, and D and 16 STs $[32,34,39]$ (Table 1), including zoonotic high-risk (HiR) extraintestinal pathogenic E. coli (HiR-ExPEC) clones ST69, ST10, and ST117 [41], while strains from the Algerian poultry sector were of ST48 and ST758 $[28,33]$, suggesting that commensal and virulent $m c r-1$-harbouring $E$. coli clones are circulating in the livestock sector in North Africa. The ST48 E. coli is a 


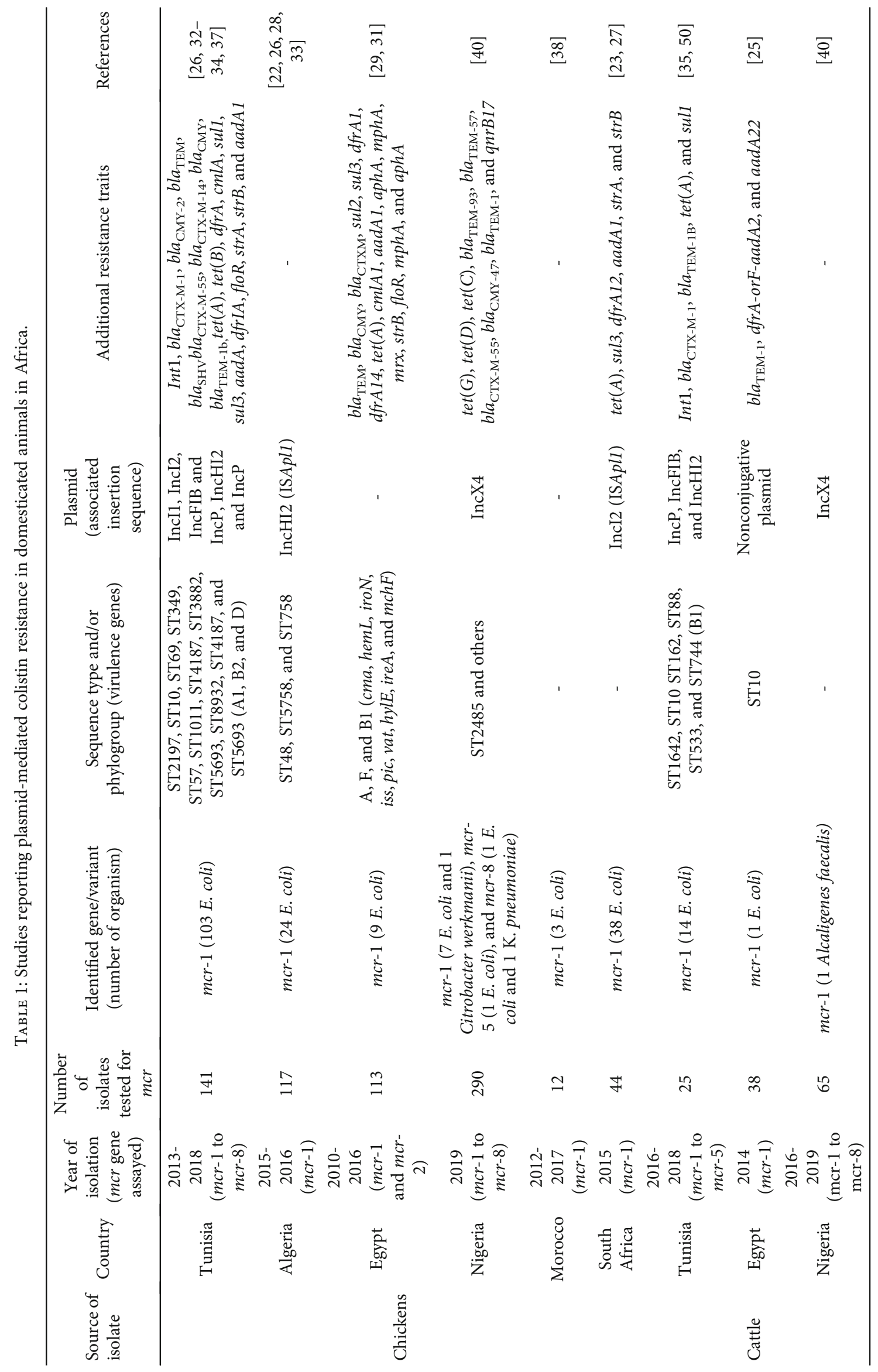




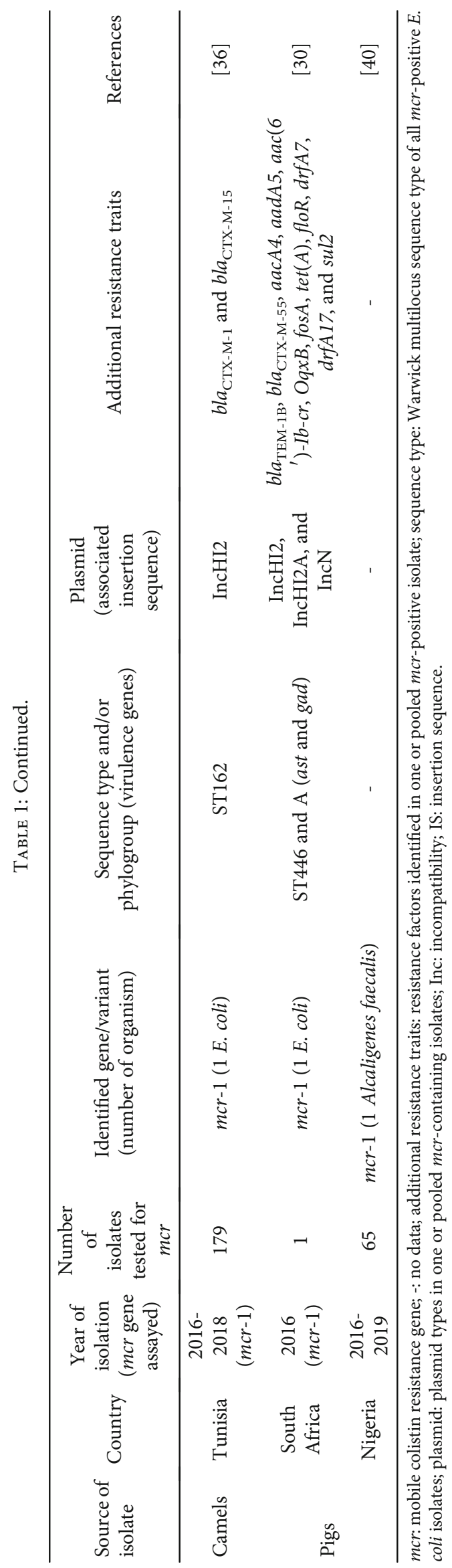


progenitor of various clones considered human associated [42], highlighting the importance of monitoring COL resistance from a One Health perspective to understand the exchange of $\mathrm{mcr}$ gene-containing bacteria (MGCB) between human-animal-environmental ecosystems in Africa.

Furthermore, $m c r-1$ was directly detected in faecal samples of 28 of 623 chickens $(0.6 \%)$ in Algeria [22, 33], suggesting that livestock/animal manure is a potential source for dissemination of COL-resistant organisms to humans (especially those that handle animals/make contact with animal manure) and the environment. Eleven $m c r$-1-carrying strains were detected among $104 \mathrm{E}$. coli (10.6\%) recovered from the $28 \mathrm{mcr}$-1-positive samples [22, 33], suggesting that direct testing of samples for $m c r$ followed by isolation is the best approach for surveillance of plasmid-mediated COL resistance in an ecological niche.

In South Africa, $38 \mathrm{mcr}$-1-carrying strains were detected among 191 E. coli (19.9\%) isolated in 2015 from chickens $[23,27]$, suggesting that $m c r-1$ is widely spread among E. coli in Southern Africa since at least half a decade ago. ISA 11 was upstream of $m c r-1$ which was located on IncI plasmid in some strains, and there were six other resistance genes in three antimicrobial families [27] (Table 1), suggesting that IncI is a common driver of COL resistance in South Africa. It is likely that $m c r$ originated in the livestock sector in South Africa since the use of COL in human medicine has been restricted as a schedule 4 drug (obtained only by prescription) in the country, whereas its use in livestock especially poultry was not restricted until 2016 [43].

In Nigeria, $m c r-1.1, m c r-5.1$, and $m c r-8$ were detected in 10 strains (nine E. coli and one Citrobacter freundii), one E. coli, and eight K. pneumoniae, respectively, among 34 isolates (55.9\%) from liver/cloacae of poultry birds [40], suggesting that diverse Enterobacteriaceae are circulating cocktails of $m c r$ genes in West Africa, which causes infections with limited choices of antibiotic therapy. The $m c r-1.1$ was located on IncX4 plasmid, and there were more than one $\mathrm{mcr}$ gene types ( $m c r-1$ and $m c r-8)$ as well as extra resistance genes (including ESBL, pAmpC, and plasmid-mediated quinolone resistance (PMQR)) belonging to four antimicrobial families in the $m c r$-positive strains (Table 1), suggesting that IncX4 is a common driver of COL resistance in Nigeria, and that organisms coproducing MCR, ESBL, and pAmpC are present in the Nigerian livestock industry. Unfortunately, conjugation was positive, implying that $m c r-1.1$ is transferable to other organisms. It is also documented that a novel $m c r-1$ variant, named $m c r-1.22$, was detected in an E. coli isolated from chicken in Nigeria (Genbank accession no. MN017134), thus further indicating that the livestock sector in West Africa is a reservoir for $\mathrm{mcr}$ genes. The presence of diverse $m o r$ genes in the Nigerian poultry sector is due to the fact that poultry farmers in the country frequently use cocktails of antimicrobials, most of which contain COL for prophylactic control/treatment of intestinal infections [44]. Thus, a policy on the restriction of nontherapeutic COL use is urgently warranted in Nigeria. However, a chromosomal mutation in $p m r B$ was detected in K. pneumoniae strains isolated from poultry in Nigeria [22], suggesting that COL resistance in West Africa is also mediated by the chromosomal mechanisms. It is also worth noting that $m c r-1.1$ was detected in threeE. coli recovered from chickens in Tanzania (https://www.ncbi.nlm.nih.gov/pathogens/antimicrobialresistance/), suggesting that $m c r-1$ is circulating in the livestock sector in East Africa. Nevertheless, it is worthy to note that none of the three isolates recovered in 2010-2012 from chickens in South Africa harboured $m c r-1$ [43]. Furthermore, none of the 93 ESBL-producing and COL-resistant E. coli isolated in 2011 from chickens in Senegal contained $m c r-1$ or $m c r-2$ [45]. However, mutation in chromosomal pmrA and $p m r B$ genes was observed in some of the strains, further suggesting that chromosomal genes are also involved in COL resistance in West Africa.

2.1.2. Pigs. African porcine sector has been reported as a potential reservoir for MGCB [30, 40]. In South Africa, a porcine ST446/phylogroup A ESBL-producing E. coli isolate carrying $m c r-1$ (on diverse plasmids) as well as 12 other resistance genes (including ESBL and PMQR genes) (Table 1) was isolated from a pig at a slaughterhouse [30]. The organism also harboured VAGs, including ast encoding heat-stable enterotoxin 1 associated with human diarrhoea [46], suggesting that the South African pig industry is a potential reservoir for virulent multi- to extensively drugresistant organisms. The presence of diarrhoeagenic $\mathrm{mcr}$ habouring E. coli in the African food chain is worrisome. This is because the treatment of food-borne diarrhoea, which is one of the most common causes of mortality among rural Africans, could be difficult if associated with MGCB. In Nigeria, one mcr-1-carrying Alcaligenes faecalis was detected among 12 faecal multidrug-resistant (MDR) isolates (8.3\%) recovered in 2016 from the rectum of pigs [40], suggesting that non-Enterobacteriaceae has been circulating $m c r-1$ in West Africa since at least 2016. COL selective pressure in the Nigerian porcine sector is likely due to the use of various antimicrobials (including colistin) without the veterinarian's supervision in the management of pigs [47]. Prophylactic antibiotic use against meningitis and sepsis (which are relatively common economic diseases in pigs caused by diverse organisms) is a potential cause of antimicrobial resistance in pigs [48]. However, other possible sources of COLresistant organisms in the African porcine sector include slaughterhouse waste (blood meal and internal organs) and fly larvae (maggots) grown in animal faeces that are often used as an economical mode for feeding of pigs [49].

2.1.3. Cattle. The presence of MGCB in the beef/dairy cattle sector in Africa has been reported [21, 25, 35, 50]. mcr-1 gene was detected in eight COL-resistant E. coli (isolated from cattle/other unreported sources) in South Africa [21]. ESBL $\left(b l a_{\mathrm{CTX}-\mathrm{M}-1}\right)$ and $\mathrm{pAmpC}\left(b l a_{\mathrm{CMY}-2}\right)$ genes were present in some of the strains, suggesting that organisms producing MCR-1, ESBL, and pAmpC have been present in Southern Africa. Studies from Northern Africa also reported plasmid-mediated COL resistance in the beef/dairy sector. In Egypt, an MDR ExPEC ST10 strain carrying $m c r-1$ on a nonconjugative plasmid and four other resistance genes belonging to two antimicrobial families (Table 1) was detected among 38 E. coli (2.6\%) isolates from cows with 
subclinical mastitis [25], suggesting low prevalence of $m c r-1$ among clinical E. coli strains from Egyptian diary sector, and that $m c r-1$ is vertically transferred among highly successful zoonotic HiR pandemic clones circulating in Egypt. However, the mcr-1-positive strain was susceptible to cephalosporins, carbapenems, and aztreonam, highlighting the need for antimicrobial stewardship in Africa to retain the efficacy of common and critically important antibiotics.

In Tunisia, 14 faecal strains carrying $m c r-1$ on IncP, IncHI, and IncFIB plasmids and class 1 integrons were detected among 25 ESBL-producing E. coli (56\%) isolated from cattle $[35,50]$, suggesting that there is a high prevalence of $m c r$-1-habouring E. coli in the Tunisian bovine sector, and that diverse MGEs evolved $m c r-1$ and ESBL genes in commensal and virulent E. coli clones in North Africa. Four other resistance genes (including ESBL gene) in three antimicrobial families were also present in the $m c r$-1-positive strains [35, 50] (Table 1), suggesting that virulent multiresistant E. coli strains are colonizing food-producing animals in the Mediterranean region. Interestingly, some of the $m c r$-1-carrying strains were recovered from calves kept in a farm where COL was used to treat diarrhoea [35], suggesting that diverse plasmid easily evolves from COL selective pressure. The $\mathrm{mcr}$ 1-positive strains were extensively diverse belonging to six STs (dominated by ST162) [35] (Table 1), including pandemic HiR-ExPEC zoonotic clones ST10 and ST88 [41], suggesting that commensal and virulent $E$. coli clones producing MCR-1 and ESBL are acquired from contaminated animal environment (such as skin of dams during suckling, feed, herbage, and drinking water).

In Nigeria, one $m c r$-1-carrying $E$. coli was detected among seven COL-resistant E. coli (14.3\%) isolated in 2016 from rectal swabs of cattle [40], further suggesting that $m c r-1$ has been present in the bovine sector in West Africa since at least four years ago. The use of cocktails of antimicrobials (most of which contain COL) in treating undiagnosed diseases by nomadic cattle herders and nonprofessionals without veterinarian's supervision [44] is the possible cause of COL selective pressure in the Nigerian bovine sector. However, the animals might have acquired MGCB through the consumption of contaminated water/herbage since cattle are reared extensively in Nigeria.

2.1.4. Camels. Camels have been reported as reservoirs of COL-resistant organisms in North Africa [36]. In a Tunisian study, one MDR ST162/phylogroup B1 ESBL-producing strain carrying $m c r-1$ and ESBL genes on a $260 \mathrm{~kb}$ IncHI2 plasmid was detected among 179 faecal Enterobacteriaceae $(0.6 \%)$ from butchery camels [36], suggesting that there is low circulation of $m c r-1$ among Enterobacteriaceae colonizing camels in Tunisia and that IncHI2 is a driver of $m c r-1$ and ESBL gene in the dromedary sector in Tunis. The ST162 $\mathrm{mcr}$-1-positive $E$. coli has also been isolated from chickens and calves in Tunisia [34, 35], suggesting that ST162 is a widely spread $m c r-1$-harbouring clone in Tunisia. The presence of MGCB in the dromedary population in Africa poses a serious danger to public health, especially to the camel handlers/tourists who make contact with them and handlers/consumers of meat from these camels. Never- theless, it is worthy to note that none of the 52 faecal Enterobacteriaceae isolated in 2011-2013 from camel (Camelus dromedarius) calves in Tunisia carried $m c r-1$ or $m c r-2$ genes [51]. Similarly, none of 162 E. coli isolated in 2017 from dromedary camels in Kenya harboured $m c r-1$ to $m c r-5$ [52]. In Nigeria, none of the three and two COL-resistant $E$. coli isolated from camels and dogs, respectively, contained $m c r-1$ to $m c r-8$ [40].

2.2. Foods of Animal Origin. Handling and consumption of contaminated foods of animal origin is a potential route for dissemination of antimicrobial resistance to human and animal populations. Inadequate husbandry and slaughterhouse facilities and unhygienic slaughtering techniques facilitate the contamination of animal-related products in Africa [53]. Six publications investigated the $\mathrm{mcr}$ gene in 211 isolates from foods of animal origin in Africa [36, 50, 54-57]. Twenty-nine strains were reported to harbour $m c r-1$ among the isolates tested.

2.2.1. Meat. Studies from North Africa reported the presence of COL-resistant organisms in samples of raw meats/readyto-eat (RTE) meat products $[34,56]$. In Tunisia, 15 strains carrying $m c r-1$ on IncP, IncFIB, and IncIl plasmids and class 1 integrons were detected among 30 ESBL-producing and COL-resistant E. coli (50\%) isolated from meat samples collected from retail stores/supermarkets [34], suggesting that diverse MGEs facilitate the spread of plasmid-mediated COL resistance through the food chain in Tunis, and that $m c r-1$ is widely spread in the poultry meat production/supply chain in North Africa. The mcr-1-positive strains were extensively diverse, belonging to four STs (dominated by ST57) (Table 2), including the pandemic HiR-ExPEC zoonotic clone ST117 [41], and they also contained 10 additional resistance genes (including ESBL and heavy metal genes) belonging to five antimicrobial families (Table 2), suggesting that handling and consumption of contaminated meat is a potential source for the acquisition of commensal and virulent clones habouring genes coding against last-resort antimicrobial(s) in Africa.

In Egypt, nine E. coli carrying $m c r-1$ and one carbapenemase-producing $\left(b l a_{\mathrm{VIM}-1}\right)$ Enterobacter hormaechei (isolated during 2017) carrying mor-9 were detected among 129 COL-resistant Enterobacteriaceae (0.8\%) isolated from samples of raw meat/RTE meat products collected from supermarkets, slaughterhouses, and butcher's shops [55-57], suggesting that farm-to-fork transmission of MGCB in Africa is facilitated by cross-contamination of meat in slaughterhouses (critical point of contamination by potentially multi to extensive resistant organisms). The $m c r-1$ and $m c r-9$ were on $64.4 \mathrm{~kb}$ IncI 2 and $250 \mathrm{~kb}$ IncHI plasmids, respectively, and there were 22 other resistance genes (including ESBL, PMQR, and heavy metal resistance genes) belonging to five antimicrobial families in the $m c r$-positive strains [55-57] (Table 2). This suggests that uncooked and half raw foods of animal origin are a source for the dissemination of multiresistant organisms coproducing MCR, ESBL, and carbapenemase in Africa, and that IncHI2 is a major driver of $m c r-9 /$ heavy metal resistance along the food 


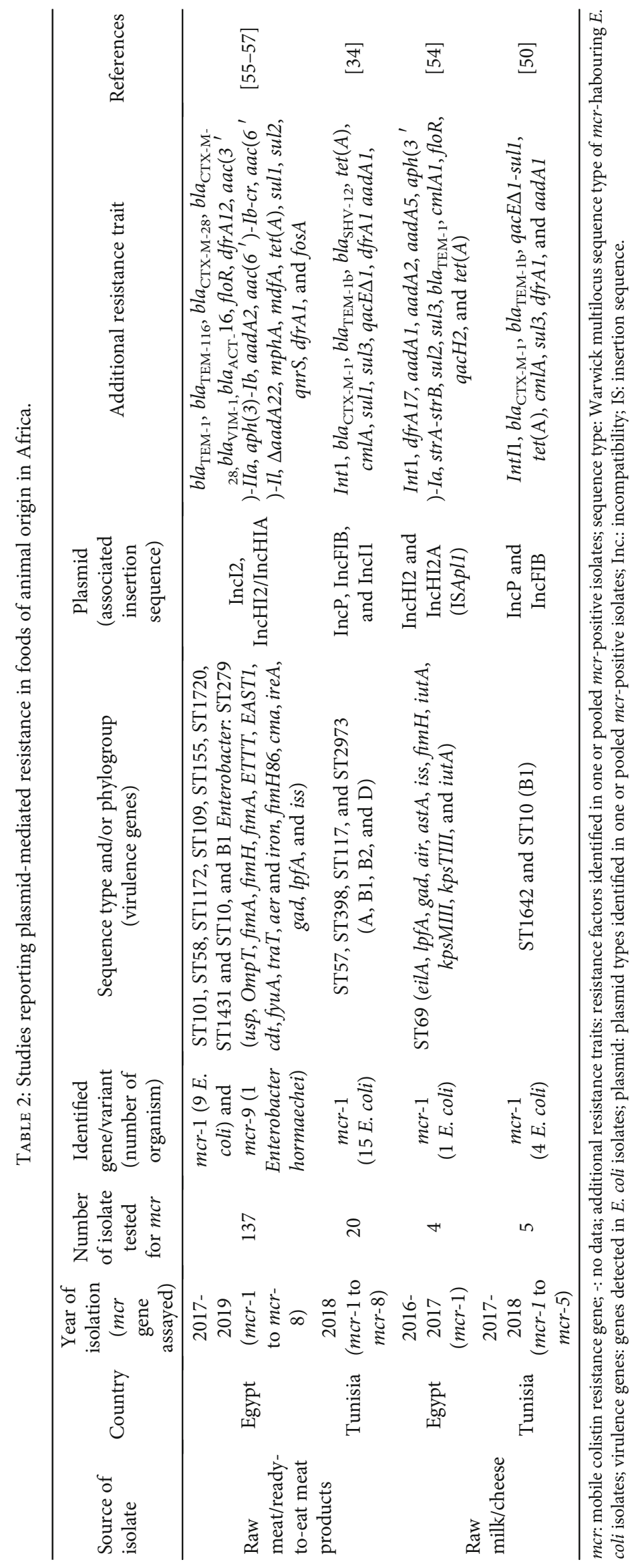


production and supply chain in the Middle East. The mcr-1positive strains were extensively diversified belonging to eight STs $[56,57]$ (Table 2), including pandemic and zoonotic HiR-ExPEC clones ST10 and ST58 (which dominated) [41], and conjugation was positive for $m c r-1$ and both $\mathrm{mcr}-9$ and carbapenem-resistance encoding gene $\left(b l a_{\mathrm{VIM}-1}\right)$ [56, 57], implying that farm-to-plate transmission is a route for the dissemination of virulent $m c r$-containing strains capable of transferring genes encoding resistance against last-resort antimicrobials to other organisms (potentially acquired through handling/consumption of uncooked food of animal origin) in Africa. The presence of organisms resistant to $\mathrm{COL}$ and carbapenems in the food chains is alarming because diseases associated with these strains are often hard-to-treat and often are untreatable. In Africa, carbapenems are not used in livestock but are used in human medicine [58]; therefore, carbapenem resistance in the food chain possibly emanated from human setting through contamination of food animals and associated products. This warrants improvement in the hygiene of slaughterhouses and their personnel in Africa. Nevertheless, it is worth mentioning that none of the 36 COL-resistant Enterobacteriaceae isolated from raw beef and chicken meat sampled in Egypt harboured $m c r-1$ [59].

\subsubsection{Dairy Products (Milk and Cheese). North African stud-} ies documented the presence of COL-resistant organisms in raw and ready-to-eat dairy products $[50,54]$. In Tunisia, one ExPEC ST10 carrying $m c r-1$ on IncP and IncFIB plasmids was detected among five ESBL-producing E. coli (20\%) isolated from samples of raw bovine/caprine milk collected from bulk-holding tanks/containers [50], suggesting that a considerable percentage of isolates from milk produced in Tunis is $m c r-1$ carriers. It also suggested that IncP and IncFIB plasmids are the common drivers of $m c r-1$ in the Mediterranean region, and that uncooked foods of animal origin (milk) are potential sources for the acquisition of MGCB. The presence of $m c r-1$-positive ST10 E. coli in food of animal origin as well as its presence in livestock [25, 34, 39], human [60], and the environment [61] in North Africa suggests that it is a highly disseminated COL-resistant ExPEC clone in the region. There were seven other resistance genes (including ESBL and heavy metal resistance genes) belonging to five antimicrobial families in the $\mathrm{mcr}$-1-positive strain (Table 2), further suggesting that the food chain is a route for the dissemination of virulent disinfectant-resistant COL-resistant organisms in Africa. The presence of disinfectant-resistant organisms in the food chain portends a substantial danger to public health, especially to handlers and consumers of raw dairy products. The use of disinfectants for washing drinking troughs and milk collection/holding containers and as foot dips in livestock farms are putative sources for heavy metal selective pressure in bacterial organisms [62]. Contaminated udder, teat, and hands of milkers are also potential sources of heavy metal-resistant organisms in milk [63].

In Egypt, $m c r-1$ flanked by ISApl1 and 14 other resistance determinants (including a heavy metal gene) were detected on IncHI2 plasmid in one pandemic HiR-ExPEC zoonotic clone ST69 among four COL-resistant E. coli (25\%) isolated from RTE raw milk cheese [49]. The organism also harboured astA genes, meaning that milk is also an important reservoir for highly virulent multi-/disinfectant-resistant organisms capable of causing difficult-to-treat diseases (diarrhoea) in Africa. It also suggested that mcr-harbouring organisms are likely evading biosecurity measures (such as disinfectant foot dips) in farms in Africa. This highlights the need for assessment of the quality of disinfectants used in livestock farms in Africa. However, possible sources of antimicrobial-resistant organisms in cheese include from contaminated animal skin (udder/teat), hands of milkers, flies, or fomites that enter into the milk during the milking process as well as from containers and preparers of the cheese [63].

2.3. Environment (Manure/Soil, Aquatic, and Wildlife Ecosystems). The environment is the receptacle of anthropogenic and agricultural wastes laden with antimicrobialresistant organisms. It is also established that the environment constitutes a substantial source for the evolution of antimicrobial-resistant organisms [64]. Thus, other ecosystems interface with the environment from/to where resistant organisms can be easily acquired or deposited. Nine publications reported on plasmid-mediated COL resistance in 582 isolates from the environment in Africa [40, 61, 65-71]. These studies reported $m c r-1$ gene-type variants in 66 isolates (51 E. coli, four K. pneumoniae, seven Pseudomonas aeruginosa, one Pseudomonas fluorescens, and three Pseudomonas species), $m c r-2$ in five isolates (one $P$. aeruginosa and two each for E. coli and K. pneumoniae), and $\mathrm{mcr}$ 3 in two E. coli strains.

2.3.1. Animal Manure/Soil Ecosystem. Dissemination of plasmid-mediated COL resistance into the manure/soil ecosystems has been documented in North Africa [61]. In an Algerian study, three ST10 mcr-1-carrying and two ST155 mcr-3-carrying strains were detected among 22 MDR COLresistant E. coli isolated from agricultural soil [61]. In the same study, two ST405 strains were detected among 20 MDR COL-resistant E. coli (10\%) isolates from animal (horse and cattle) manure. These findings suggest that pandemic HiR-ExPEC zoonotic clones have disseminated diverse $\mathrm{mor}$ genes from the livestock ecosystem through animal manure into the soil ecosystem in Algeria. There was an ESBL gene in some of the strains [61] (Table 3), suggesting that organisms coproducing MCR-1 and ESBL have disseminated into various environmental ecological niches in North Africa. It also suggested that pandemic HiR-ExPEC zoonotic clones [41] producing ESBL and MCR-1 might be circulating in the Algerian equine and bovine industries. However, since COL is not known to be used in horses in Tunisia, COL selective pressure in Tunisian equine sector possibly emanated from the use of other antibiotics [72]. Nevertheless, the animals could also have acquired organisms from persons (such as groomers, caretakers, and jockeys) who are often in contact with them and/or through the consumption of contaminated herbage or fluid. It is very likely that MGCB in the sampled agricultural soil in Algeria originated from 


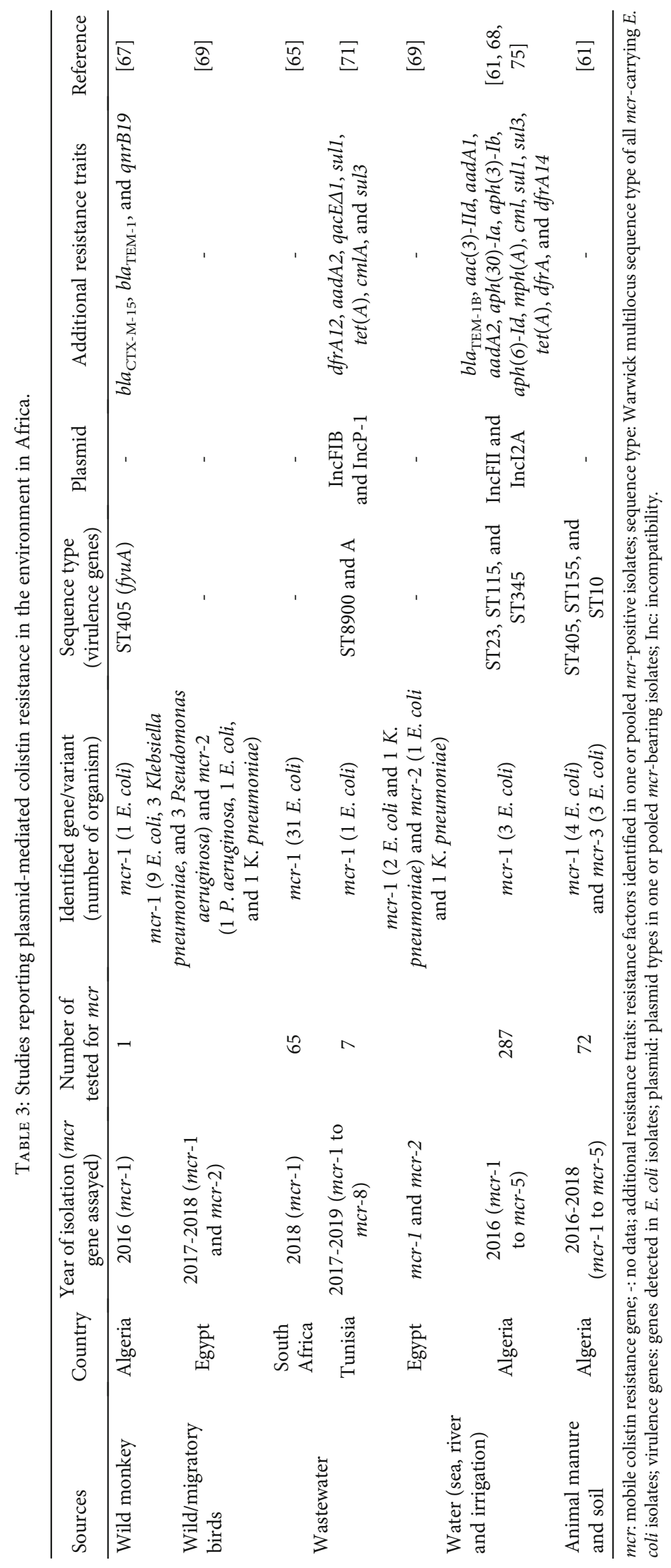


untreated or insufficiently treated animal manure used as organic fertilizer in the farmlands. Runoffs can potentially carry MGCB from the soil to aquatic ecosystems (such as surface waters and aquacultures), and rainfall drops could also raise resistant organisms from the soil to plants, thereby contaminating these niches and posing a risk to public health [19]. Encouragingly, it has been reported that composting and anaerobic digestion is effective in eliminating $\mathrm{mcr}$ in animal manure [73]. However, garbage flies could also have picked the COL-resistant organisms from other places and subsequently deposited them on the animal manure during feeding/breeding [19]. However, more worrisome is that conjugation was positive, implying that the isolates could rapidly transfer $m c r-1$ to other organisms. Therefore, individuals (humans and animals) who make contact with animal manure and soil as well as those who handle/consume raw/undercooked plant products (such as vegetables) are at great risk of acquiring $\mathrm{mor}$ genes. Unfortunately, in Africa, the majority of farmers work manually without personal protective equipment and vegetables are often consumed raw or undercooked. Thus, farmers and consumers of raw/undercooked contaminated vegetables/farm crops in Africa are at greater risk of infection by COL-resistant organisms present in manure/soil.

\subsubsection{Aquatic Ecosystem}

(1) Wastewater. Wastewaters are contaminated fluids from anthropogenic and agricultural settings, which contain nutrients that support the growth of bacteria and rapid exchange of MGEs [74]. Thus, wastewaters are established sources of new emerging pathogenic antimicrobial-resistant organisms. Wastewaters have been reported as a reservoir of MGCB in Africa $[65,66,71]$. Thirty-one MDR E. coli carrying mcr-1 and daaE gene (associated with human diarrhoea) were isolated from municipal wastewater effluents in South Africa [65], suggesting that COL-resistant potentially escapes the wastewater treatment methods used in South Africa. This finding of $\mathrm{mcr}$ positive organisms in wastewater is worrisome because the health of the public is in danger as this insufficiently treated wastewater may eventually be released into surface water bodies and farmlands thereby contaminating terrestrial/aquatic wildlife, soil, and humans through contact with the environment or food chain. Thus, improvement in wastewater treatment protocols in Africa is warranted.

In the Republic of Congo, eight $m c r$-1-carrying strains (four $P$. aeruginosa, one $P$. fluorescens, and three Pseudomonas spp.) were detected among 20 MDR Pseudomonas (20\%) isolated in 2017 from community wastewaters [66], suggesting that $m c r-1$ has disseminated in the human population in East Africa since at least three years ago. Because of the poor wastewater treatment facilities in Congo-Brazzaville (like in most sub-Saharan African countries), MGCB emanating from human wastewaters can easily disseminate into other ecosystems. Thus, there is a need for improved hygiene and waste management in Congo-Brazzaville, a country whose infrastructural facilities were overstretched due to a prolonged/recurrent civil war.
In Tunisia, one ST8900/phylogroup A E. coli carrying $m c r-1$ and an ESBL gene ( $b l a_{\text {CTX-M-15 }}$ ) on IncFIB and IncP1 was detected among seven ESBL-producing and COLresistant Enterobacterales (14.3\%) isolated from raw wastewater collected from a wastewater treatment plant (WWTP) receiving wastewater from diverse sources (domestic, hospital, urban, rain, and industrial waters) [71]. This suggests that diverse promiscuous plasmids have widely spread $m c r-1$ among Enterobacterales colonizing humans in Tunisia, and that environmental dissemination of plasmid-mediated COL resistance in the country originates from anthropogenic/agricultural settings. ISApl1 and pap2 flanked the $m c r-1$ upstream and downstream, respectively, while class 1 integrons harbouring other resistance genes, including heavy metal resistance gene, were also present in the $\mathrm{mcr}$-1-positive strain (Table 3). This implies that diverse genetic elements facilitate the spread of $m c r-1$ in North Africa, and that WWTPs are hotspot collectors of MDR Enterobacterales in the Mediterranean region. This further highlights the need for adequate treatment of wastewaters before discharge into the environment.

(2) River and Seawaters. The presence of MGCB in natural water in North Africa has been reported [68]. In Algeria, two tigecycline-resistant E. coli of ST115 and ST23 strains carrying $m c r-1.1$ on IncHI2A and $m c r-1.5$ on IncI2 plasmid, respectively (Table 3), were detected among 246 COLresistant isolates $(0.8 \%)$ from seawater polluted with domestic, hospital, agricultural, and industrial wastes $[68,75]$, suggesting that pandemic HiR-ExPEC zoonotic clones [41] have disseminated from anthropogenic/agricultural settings (due to improper disposal of wastes) into water bodies in the Mediterranean region. The worse is that the strains contained 14 resistance genes in four antimicrobial families [75] (Table 3), indicating that seawater in Africa is a reservoir of cocktails of multiresistance genes. Surface waters containing COLresistant pose a substantial threat to public health, especially to the coastal dwellers in Africa that use these waters for various purposes including food processing, recreation, drinking, fishing, laundering, and bathing [19]. Remarkably, the organisms did not transfer $m c r-1$ to a recipient organism [68], suggesting that the plasmidal location of a $\mathrm{mcr}$ gene does not necessarily imply its transferability. Since tigecycline is the last-line antibiotics used for treating deadly infections, the presence of tigecycline-resistant and COL-resistant organisms in the natural environment can complicate the dynamics of antimicrobial resistance in Africa. Thus, surveillance of tigecycline resistance in diverse ecological niches in Africa is warranted. It is also worth noting that $m c r-5.1$ and novel $m c r-3$ genes, named $m c r-3.33$ to $\mathrm{mcr}$-3.37, were detected in Aeromonas strains recovered from rivers (receiving wastes from communities) and storm waters in South Africa (https://www.ncbi .nlm.nih.gov/pathogens/antimicrobial-resistance/), suggesting that in South Africa, environmental waters are reservoirs of $m c r-3$ and $m c r-5$ possibly originating from anthropogenic/agricultural settings.

(3) Irrigation Water. The presence of COL-resistant bacteriain irrigation water has also been reported in North Africa. 
An MDR ST345 mcr-1-carrying strain was detected among 31 COL-resistant E. coli (3.2\%) isolated from irrigation water in Algeria [61], further suggesting that $m c r-1$ disseminated from agricultural/anthropogenic settings into surface waters in Algeria. Contaminated irrigation water is a source for the contamination of plants and soil, thereby posing health risks to farmers and consumers of raw/undercooked plant materials. Moreover, MGCB in the Algerian irrigation system can disseminate into the Mediterranean Basin, contaminating farmlands and plants, thus posing a risk to public health [19].

2.3.3. Wildlife. Wildlife has been reported as a potential reservoir for COL-resistant organisms in Africa. In Algeria, a faecal ST405/phylogroup D mcr-1-carrying E. coli was isolated from a Barbary macaque monkey (Macaca sylvanus) [67], suggesting that a pandemic HiR-ExPEC zoonotic clone is circulating COL resistance in the wild in North Africa. Genes encoding ESBL and PMQR were also present in the strain, suggesting that wild animals in Africa are potential disseminators of genes conferring resistance to last-resort antibiotics. The genome of the ST405 strain did not conjugate with that of a recipient organism, suggesting that the mcr-1 might be located on the chromosome or nonconjugative plasmids, hence can be vertically transferred and maintained/persist in the wild. Since antibiotics are not used in wildlife, anthropogenic and agricultural wastes that contaminated plants or fluids consumed by the monkey are possible sources of $m c r-1$ in the wild [19]. The ST405 E. coli clone is associated with global dissemination of ESBL [67]. MCR-1producing ST405 ExPEC clone was associated with diseases in humans in Algeria [76, 77], and it has been found in livestock and the environment in the country [28,61], thus suggesting that this organism is circulating in human/anima1/environmental ecosystems in North Africa.

The role of wildlife in the dissemination of $\mathrm{mcr}$ in the environment and human population has been reported in Africa [69]. In Egypt, 15 (12.3\%) mcr-1-carrying strains (nine E. coli, three each for K. pneumoniae, and P. aeruginosa) and three $(2.5 \%)$ mcr-2-carrying strains (one each for E. coli, $K$. pneumoniae, and $P$. aeruginosa), respectively, were detected among 122 isolates from wild (resident/migratory) birds [69], suggesting that diverse organisms (Enterobacteriaceae and non-Enterobacteriaceae) habouring different $\mathrm{mor}$ gene types are colonizing wildlife in North Africa. The resident birds probably picked the MGCB from an environment contaminated with anthropogenic/agricultural wastes, while the migratory birds possibly picked organisms from other places and transported them to Algeria. More worrisome is the fact that three (16.7\%) mcr-1-carrying (two E. coli and one K. pneumoniae) and two (11.1\%) mcr-2-harbouring (one each for E. coli and K. pneumoniae) strains were detected among 18 isolates from environmental waters, which were in close proximity to the habitations of the wild birds, suggesting that the birds possibly disseminated the COL-resistant organisms into these waters. Even worse is that two (6.5\%) strains (one each for E. coli and K. pneumoniae) carrying $\mathrm{mcr}$ - 1 and three (9.7\%) strains (one E. coli and two K. pneumoniae) carrying $m c r-2$ were detected among 31 isolates (16.1\%) from humans living close to the water bodies, suggesting that these individ- uals might have acquired $\mathrm{mcr}$ genes from the contaminated waters. Anthropogenic (laboratory, home, and human wastes from swimmers and ships) and agricultural runoffs are also potential sources of COL-resistant organisms in the surface waters. There were both $m c r-1$ and $m c r-2$ in some isolates from migratory wild birds and humans, suggesting that surface waters in Africa are potential reservoirs for cocktails of mor genes, thus posing a risk to public health. It also suggested that in Africa, the aquatic environment is a good medium for rapid acquisition and transfer of $\mathrm{mcr}$ genes.

African wildlife has been noted as potential vectors for intercontinental dissemination of COL-resistant organisms. One ST48 strain carrying $m c r-1$ on a $65 \mathrm{~kb}$ IncI plasmid was detected among 29 faecal ESBL-producing E. coli (3.4\%) isolated from fennec foxes (Vulpes zerda) exported to China from Sudan [70], suggesting that organisms coproducing MCR-1 and ESBL have disseminated into the wildlife in Sub-Saharan Africa, and that wildlife trade is a route for dissemination of plasmid-mediated COL resistance. More worrisome was the fact that the strain transferred $m c r-1$ to a recipient organism, and it also contained 11 resistance genes, including genes encoding resistance to $\beta$-lactams (blaTEM and $\left.b l a_{\text {CTX-M-64 }}\right)$, fosfomycin (fos $\left.A\right)$, tetracycline (tet $\left.A\right)$, folate-pathway antagonists (sul1, sul2, and $d f_{r} A$ ), aminoglycosides ( $m p h A$ and $m d f)$, phenicols (floR), and PMQR $(o q \times B)$. This means that wildlife is a potential reservoir for organisms that can transfer genes encoding resistance to last-resort antimicrobials to other organisms, thus posing a risk to public health, especially to those that interact (handle/consume) with wildlife. It was not reported whether the foxes were fed and/or given water before sampling in China. $m c r-1$ is highly endemic in China, especially in foods of animal origin with which the foxes could have been fed. Nevertheless, $m c r-1$ is very likely originated from the agricultural/anthropogenic setting in Sudan. Thus, there is a need for surveillance of COL resistance during imported wildlife quarantine. It is worthy to mention that $m c r-1$ was not detected in one COL-resistant K. pneumoniae isolated from the hospital environment in Nigeria [40].

2.4. Humans. Humans interface with animal and environmental ecosystems. Thus, they can deposit (through various anthropogenic activities) and acquire (through consumption of and contact with contaminated foods, fomites, and environment) antimicrobial-resistant organisms from these other ecosystems. Thirty-two studies probed $\mathrm{mcr}$ in 1,320 isolates from humans in Africa and reported $m c r-1$ gene-type variants in 113 isolates (24 K. pneumoniae, 71 E. coli, 15 Pseudomonas, two Acinetobacter baumannii, and one Enterobacter), mcr- 8 in 6 K. pneumoniae, and mcr-9 in two Enterobacter hormaechei.

The dissemination of MGCB in human populations in Sub-Saharan Africa has been reported [40, 66, 77-87]. Five $m c r$-1-carrying strains (three $P$. aeruginosa and one each for P. luteola and P. putida) were detected among 14 clinical MDR Pseudomonas (35.7\%) isolated from persons in the Republic of Congo [66], suggesting that $m c r-1$ is widely spread among non-Enterobacteriaceae circulating in the human population in Central Africa. Overuse of 
antimicrobials due to increased traumatism and high disease burden resulting from a prolonged and persistent civil war are factors that possibly prompted the development of COL-resistant organisms in Congo-Brazzaville.

The presence of MGCB in hospitalized individuals in East Africa has been reported [78-81]. In Sudan, 13 strains (seven E. coli, five K. pneumoniae, and one Pseudomonas) carrying $m c r-1$ were detected among 285 clinical MDR Enterobacteriaceae (4.6\%) isolated in 2016 from individuals $[78,79]$, suggesting low circulation of $m c r-1$ among diverse organisms (Enterobacteriaceae and non-Enterobacteriaceae) colonizing individuals in East Africa since at least four years ago. In Kenya, a hospital-associated HiR ST15 K. pneumoniae (isolated during 2017) which harboured $m c r-8$ and 27 other resistance genes (including ESBL, PMQR, and fosfomycin resistance genes) (Table 4) on IncHI1B and IncR plasmids was isolated from a patient [80], indicating that uncommon plasmids are spreading $\mathrm{mcr}$ among virulent organisms in Africa, and that hospitalization (due to lack of antimicrobial stewardship and poor healthcare infrastructures) is a potential risk for the acquisition of MGCB in the continent. In Tanzania, 11 ST46 strains carrying mcr-1.1 (on a $33 \mathrm{~kb}$ IncX4 plasmid) and 18 other resistance genes (including ESBL gene) (Table 4) were detected among 20 faecal COL-resistant MDR E. coli (55\%) isolated in 2017 from healthy persons working in hotels in Zanzibar Tanzania [81]. This indicates high community transmission of organisms coproducing MCR-1 and ESBL in Tanzania since at least 2017, and that places frequented by tourists in Africa are fertile niches for the exchange of MGCB between the hosting community population and the travelers. Possible causes of gut colonization of hotel workers by COLresistant organisms include frequent empirical use of drugs without prescription, uncontrolled use of antibiotics, including COL in food and animal settings, and limited sanitation of the food chain [81].

Evidence that $\mathrm{mcr}$ genes has disseminated into the human ecosystem in West Africa has been documented [40, 82]. Nine (five K. pneumoniae and four E. coli) and three strains carrying $m c r-1$ and $m c r-8$ (K. pneumoniae), respectively, were detected among 78 clinical Enterobacteriaceae $(17.9 \%)$ from individuals in Nigeria $[40,82]$ indicating that diverse $\mathrm{mor}$ genes have disseminated into the human ecosystem in West Africa. It is very likely that MGCB disseminated from the livestock sector to the human population in Nigeria since COL for human medicine is not known to be used in the country.

South African studies also reported the circulation of $\mathrm{mcr}$ in the human population [83-87]. Twenty-five strains (17 E. coli and five Klebsiella carrying $m c r-1$ and three ESBLproducing COL-susceptible Enterobacter hormaechei carrying $m c r-3)$ were detected among 59 clinical Enterobacteriaceae $(42.4 \%)$ isolated from individuals in South Africa [8387], indicating high prevalence of $\mathrm{mcr}$ among diverse Enterobacteriaceae colonizing humans in South Africa. The mcr-1 was flanked upstream by ISApl1/IS 28 on $30-75 \mathrm{~kb}$ IncI2, IncHI2, and IncX4 plasmids [84], $m c r-9$ was also on IncHI2 plasmid [87], and there were 40 antimicrobial determinants (including $\mathrm{ESBL}$ and $\mathrm{pAmpC}$ genes) in the $m c r$-positive strains. The $m c r-1$-positive $E$. coli isolates belonged to six STs (dominated by ST624) [83-85] (Table 4), including pandemic HiR-ExPEC zoonotic clone ST10 [41]. These findings suggest that diverse genetic elements (especially IncHI plasmids) drive $\mathrm{mcr}$ and genes coding resistance to last-resort antimicrobials in commensal and virulent clones in South Africa. Some of the $m c r$-1-positive strains transferred $m c r-1$ to a recipient organism [84], suggesting that $m c r-1$ could be rapidly transferred to other organisms. Interestingly, some of the individuals who yielded mor-1-positive strains had never received COL therapy, and some of them had never received antibiotic treatment [83]. Thus, suggesting that the dissemination of organisms producing MCR-1 into the human population in South Africa is very likely originated from the livestock sector. However, prior visits to the hospital for more than six months, carbapenem and fluoroquinolone therapy, antiviral therapy, and organ transplant were factors that could also have prompted the acquisition of $m c r-1$ by the organisms [83]. It was also reported that some of the $\mathrm{mcr}$-1positive strains exhibited carbapenem resistance, but one of them was susceptible to all tested antimicrobials [86], thus suggesting that the mor genes can be harboured by COLresistant isolates that are susceptible to other antibiotics. Furthermore, the COL susceptibility exhibited by mcr-9-habouring Enterobacter strains is associated with the lack of qseB/qseC gene, which induces COL resistance in $m c r-9$-containing strains [88]. However, the strains possessed mutations in the chromosomal genes $m g r B$ and $p m r B$, further suggesting that $\mathrm{mcr}$ and chromosomal genes are responsible for COL resistance in Africa. Although the $m c r-9$-positive strains were related, they differed from all other African isolates, suggesting that they have been imported into South Africa, possibly following medical tourism to other countries. Therefore, screening and surveillance of tourists, especially those who visited areas with high $m c r$ endemicity, are warranted. The colonization of humans in Sub-Saharan Africa by MGCB calls for serious concern; this is because these organisms could easily disseminate into the environment/other ecosystems following unhygienic practices like open air defecation which is still common in the region.

Studies from North Africa also reported humans as reservoir for COL-resistant organisms [28, 60, 76, 77, 89-97]. In Egypt, 20 strains (six E. coli, nine Pseudomonas aeruginosa, three K. pneumoniae, and two Acinetobacter baumannii) carrying $\mathrm{mcr}-1$ and one tigecyline-resistant Enterobacter hormaechei (isolated during 2015) carrying mcr-9 on IncHI2 plasmid were detected among 285 clinical MDR isolates (7\%) from individuals [89-95], suggesting low circulation of $\mathrm{mcr}$ genes among Enterobacteriaceae and non-Enterobacteriaceae causing difficult-to-treat diseases in Egypt, and that organisms producing MCR-9 had been present in North Africa, since at least half a decade. It also suggested that organisms in the ESKAPE (Enterococcus, Staphylococcus, K. pneumoniae, Acinetobacter baumannii, $P$. aeruginosa, and Enterobacter) group, which are highest-priority clinically relevant organisms, are circulating $\mathrm{mcr}$ genes in Africa. The presence of $m c r$-carrying strains of ESKAPE (especially $P$. aeruginosa and A. baumannii) in Africa portends a substantial challenge to public health (due to increased disease 


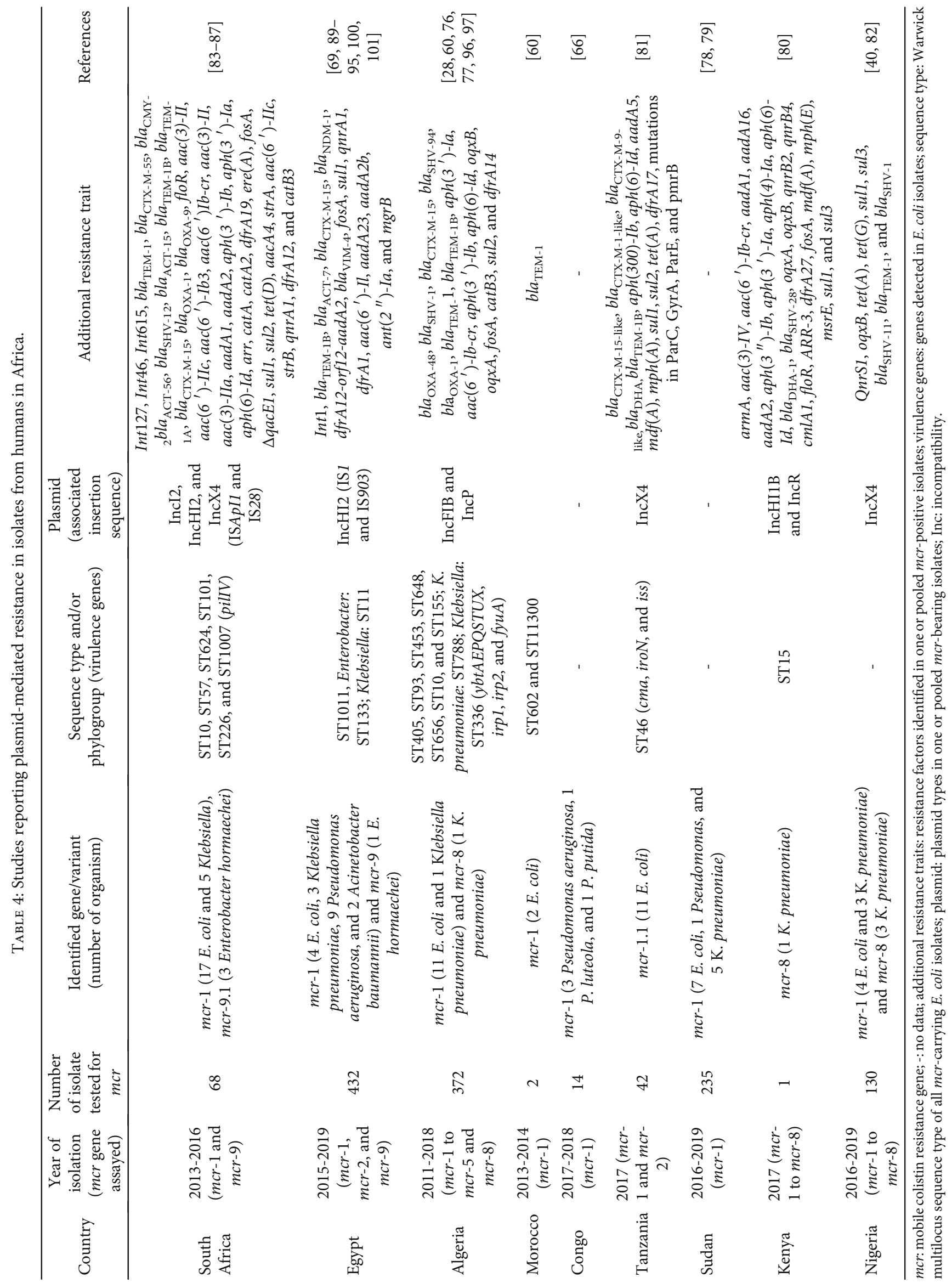


burden and cost of hospital stay/treatment) because various intrinsic and acquired traits enable these organisms to exhibit resistance to many antibiotics, including the critically important ones, and they represent the most causes of difficult-totreat nosocomial infections worldwide $[98,99]$. Some of the $m c r$-1-positive strains were recovered from individuals without a travel history [91], persons with healthcare-associated infections [89], and those who took antibiotics one month before hospitalization [95]. Thus, suggesting that antibiotic consumption is a putative risk for the development of carbapenem-resistant and COL-resistant bacteria, and that these organisms are disseminated from the community to the hospitals and vice versa in Africa. Class 1 integron was present in one $m c r$-1-positive E. coli [91], and there were IS903 and IS1 upstream and downstream of $m c r-9$, respectively. Moreover, there were 15 extra resistance genes (including ESBL, carbapenemase, and PMQR genes) belonging to five antimicrobial families in the $\mathrm{mcr}$-positive strains $[91,94]$ (Table 4). These findings indicate that diverse genetic elements (plasmids, transposons, and integrons) facilitate the acquisition and transfer of $\mathrm{mcr}$ and genes coding resistance to last-resort antimicrobials in Africa. Unfortunately, the genome of some of the $m c r-1$ - and $m c r$-9-positive strains conjugated with that of recipient organisms [91, 94], implying that the genes could be transferred to other organisms (easily in the gut), thus posing a worrisome risks to public health. Since MCR-9/carbapenemase-producing Enterobacter hormaechei has also been detected in food of animal origin in Egypt [57] and humans in South Africa [87], it means that Enterobacter is a prolific trafficker of $m c r-9$ and that handling/consumption of contaminated animal-related products is a potential route for transmission of this organism into the human ecosystem in Africa.

In Algeria, four E. coli (isolated in 2011) carrying mcr-1 and one virulent ST3336 K. pneumoniae (isolated in 2018) which harboured $m c r-8$ and 15 other resistance determinants (including ESBL, carbapenemase, and PMQR genes) in six antimicrobial families (Table 4) were detected among 276 clinical Enterobacteriaceae (1.8\%) isolated from individuals, including a person without history of travel $[28,76,77,96$, 97], suggesting that there has been a low community transmission of organisms coproducing MCR, ESBL, and carbapenemase in human population in Algeria since at least nine years ago. This portends a grave danger to public health due to the possibility of limited antimicrobial therapy for managing infections associated with organisms coproducing MCR, ESBL, and carbapenemase. The $m c r-1$ was flanked downstream by ISApl1 on $140 \mathrm{~kb}$ IncFIB and IncP plasmids in some of the strains belonging to the ExPEC clone ST405 $[28,76,77]$, thus suggesting that diverse genetic elements (transposons and plasmids) evolved $m c r-1$ among pandemic HiR-ExPEC zoonotic clones causing difficult-to-treat diseases in humans in Algeria. The mcr-1-positive ST405 E. coli is very likely disseminated into Algerian human and environmental ecosystems from the animal sector since COL is frequently used in livestock husbandry in Algeria [28]. Unfortunately, the ST405 E. coli strain can rapidly transfer $m c r-1$ to other organisms, having transferred the gene to a recipient organism at a frequency of $10^{-7}$ cells/recipient [28,
76, 77]. Nonetheless, one of the $m c r-1$-positive isolates did not transfer $m c r-1$ to a recipient organism, suggesting that the gene was located on the chromosome or nonconjugative plasmid in the mcr-1-positive strain; hence, it can be vertically transferred and maintained in the human population, thereby posing a worrisome risk to public health. Moreover, it was reported that $m c r-1$ was stable in the isolates after 30 subculture passages [28], suggesting that the gene can persist in different ecological niches for a long time.

The role of travelers in the importation of mcr into Africa has been reported [60]. $m c r-1$ was detected in rectal swab samples of 23 among 440 individuals (5.2\%) who performed the pilgrimage (Hajj) to Mecca after their return to their home countries of Morocco and Algeria [60], suggesting that overly crowded multinational events represent a fertile niche for the rapid transmission of $\mathrm{mcr}$ between individuals who subsequently carry these genes back to their countries [20]. Only 10 Enterobacteriaceae (nine E. coli and one ST788 K. pneumoniae) carrying $\mathrm{mcr}$ - 1 were isolated from the $23 \mathrm{mcr}$ 1-positive samples, suggesting that by isolation alone, the magnitude of plasmid-mediated COL resistance in an ecological niche can be underestimated. Extensive diversity existed among the mcr-1-positive E. coli isolates, which belonged to six STs dominated by pandemic HiR-ExPEC zoonotic clones ST10 and ST648 (Table 4), suggesting that traveling is a route for dissemination of virulent $E$. coli clones capable of causing difficult-to-treat diseases.

African residents have been noted as potential transporters of $m c r$ to other places [100]. An ESBL-producing Enterobacter cloacae harbouring $m c r-1$ was isolated from an Algerian hospitalized in France [100]. Although it was reported that the patient did not travel to Algeria for many years, there is a possibility that the patient's gut was colonized before traveling to France since there was no reported history of the patient having contact with livestock in France. Thus, there is a need for a globally coordinated effort to combat the spread of the $m c r$ genes through travel [20].

Traveling to Africa has also been noted as a putative risk of acquisition of MGCB [101, 102]. An ESBL-producing pandemic HiR-ExPEC zoonotic clone ST410 carrying $m c r-1$ on IncI plasmid was isolated from the urine samples of an American who traveled to Kenya and China [101], further suggesting that virulent MGCB can be acquired in Africa through the consumption of foods of animal origin or contact with livestock/fomites contaminated with COLresistant organisms. However, there is also a possibility that the American acquired the organism in China. An ESBLproducing E. coli and Salmonella Virchow carrying $\mathrm{mcr}-1$ (flanked upstream by ISApl1) on IncI2 and IncHI2 plasmids, respectively, were isolated in the United Kingdom from patients who traveled to Egypt [102], further supporting that travelers to Africa can contract MGCB from the region and transport them back to their countries.

\section{Conclusions}

This review showed that the diversity of organisms such as $E$. coli, Salmonella, Klebsiella, Citrobacter, Enterobacter, Pseudomonas, Aeromonas, Acinetobacter baumannii, and 


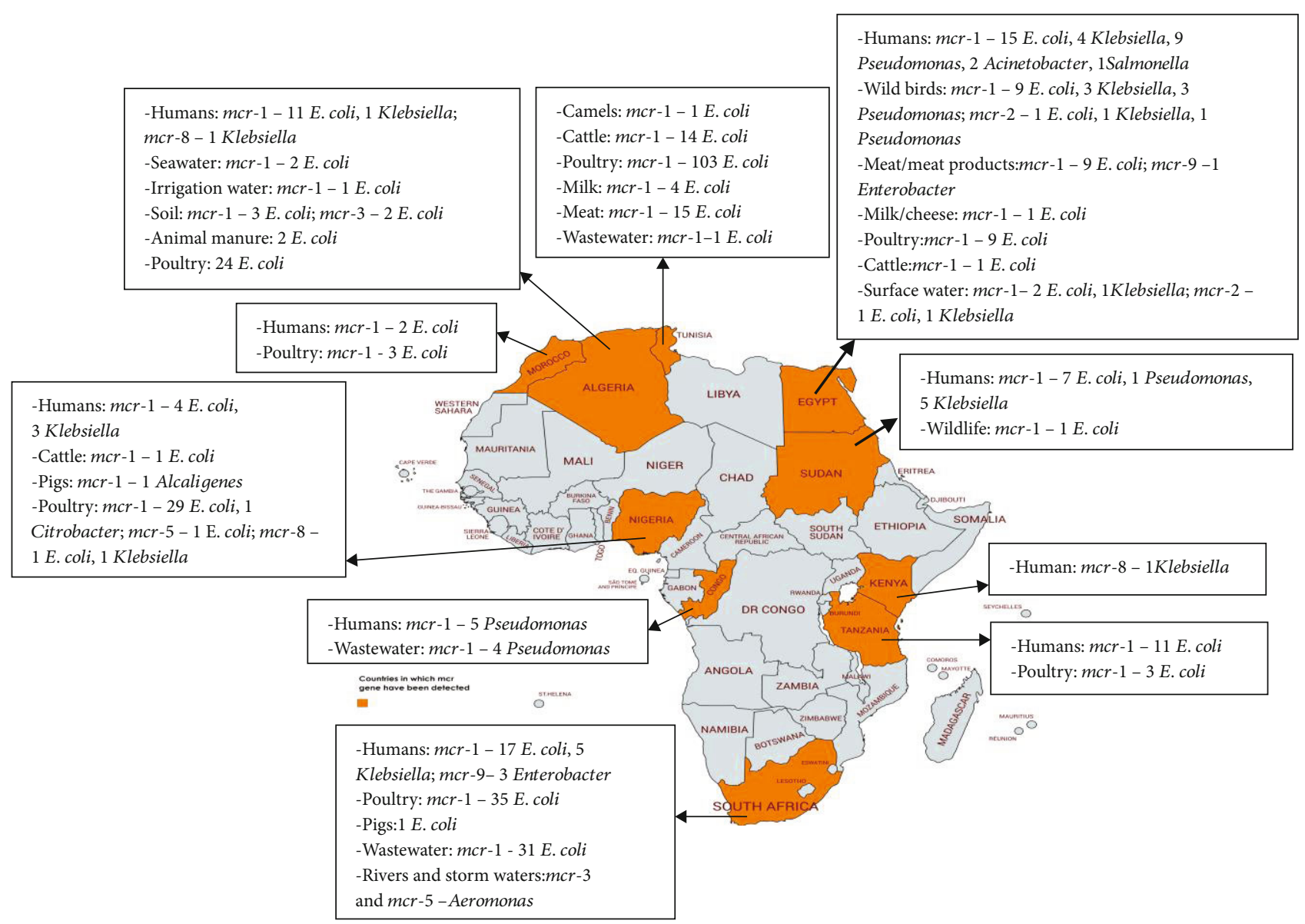

FIGURE 1: Distribution of organisms containing mor genes in Africa. This map was created using an online service (https://mapchart.net/).

Alcaligenes faecalis habouring various $\mathrm{mcr}$ genes is widely spread in humans, animals, food of animal origin, and environmental (manure/soil, aquatic, and wildlife) ecosystems in Africa (Figure 1). E. coli is the predominant organism spreading $m c r$ genes in Africa, and $m c r-1$ is the most trafficked COL resistance gene in the continent. The oldest $\mathrm{mcr}$-containing isolates from Africa are E. coli isolated in 2010 from chickens in Egypt [29]. In Asia, the oldest mcr-harbouring isolates were E. coli recovered in 1980 from food-producing animals in China [103], while the oldest $m c r$-containing isolates from Europe were E. coli strains of bovine origin recovered in 2004 in Italy [104]. Inappropriate use of antimicrobial agents in humans and animals, anthropogenic activities such as defecation in open environment/water and bathing/swimming in water bodies, and improper disposal of untreated as well as insufficiently treated animal manure, slaughterhouses, home, hospital, and laboratory wastes are the major causes of development of COL-resistant organisms and dissemination of $m c r$ genes in Africa. Circulation of COL-resistant bacteria in human population in Africa is concerning because, if carbapenemase genes are present in the isolates, COL is one of the only options left for the treatment of human infections [105]. The presence of MGCB in natural water bodies in Africa is evidence that the anthropogenic burden of COL use resulted in environmental contamination in the continent. This can complicate the transmission dynamics of
COL-resistant organisms and the rate of evolution of plasmid-mediated COL-resistant strains. Isolates from Africa carry $m c r$ genes, together with many virulence and resistance genes, including those coding resistance to critically important antimicrobial agents. These organisms are superbugs that can potentially cause difficult-to-treat infections with pandemic potential. Some African isolates have acquired mega-plasmids with numerous ARGs (some harbour $\geq 10$ genes). The presence of floR gene encoding florfenicol (an antibiotic that is only used in veterinary medicine) resistance in some African isolates (Table 4) suggests that veterinary usage of COL possibly prompted the acquisition of $\mathrm{mor}$ in the isolates. Thus, a policy on the ban of nontherapeutic COL use is urgently warranted to curb the development and spread of plasmid-mediated COL resistance in Africa. Since there is very limited access to effective antimicrobials capable of destroying COL-resistant organisms in Africa, the development of effective antimicrobial stewardship programs and the use of nonantibiotic alternatives such as probiotics and antimicrobial peptides in the management of livestock are crucial to prevent an increase in the development of COL resistance and prevalence of MGCB in Africa. Since some of the $m c r$-negative isolates in this review may contain $\mathrm{mcr}$ genes that were undetectable by screening methods used in the various studies, surveillance monitoring of $m c r$ using high-throughput techniques (such as whole 
genome sequencing) is important to determine the actual magnitude of PMCR in Africa.

Diverse genetic elements, including conjugative and nonconjugative plasmids, class 1 integrons, transposons, and insertion sequences, are driving the horizontal/lateral transmission of plasmid-mediated COL resistance in Africa. IncHI2, IncI2, IncFIB, and IncP are the predominant plasmids facilitating the spreading of $m c r$ genes in Africa. The mor genes carried by African strains can spread worldwide since the genes were transferred to recipient strains. Nonetheless, $m c r-1$ and $m c r-3$ have integrated into the chromosomal DNA and nonconjugative plasmids in African strains, enabling their vertical transmission and persistence among clonal lineages. Transmission of the $\mathrm{mcr}$ genes among strains from Africa is nonclonal even among diverse zoonotic virulent pandemic enterobacterial clones. More worrisome is that $\mathrm{mcr}$ has disseminated into the wild in Africa; this is an indication that $\mathrm{mcr}$ is maintained in bacterial populations in Africa regardless of antimicrobial selective pressure. Indeed, through horizontal/lateral and vertical transfer, $\mathrm{mcr}$ genes (mcr-1, $m c r-2, m c r-3, m c r-5, m c r-8$, and $m c r-9)$ have spread widely into diverse ecosystems in Africa. These $\mathrm{mcr}$ genes are potentially exported from Africa to other continents through international travel, animal/plant, and food trade. This further underlines the need for globally coordinated One Health approaches.

\section{Conflicts of Interest}

The authors declare no conflict of interest.

\section{Authors' Contributions}

MUA designed the study and prepared initial draft of the manuscript. CORO, KFC, and SVS proofread the manuscript and improved its intellectual content. Both KFC and SVS supervised MUA. All authors have read and agreed to the final version for submission.

\section{Acknowledgments}

CORO appreciates financial (Incentive+Power) support from Wroclaw University of Environmental and Life Sciences, Poland. The publication was financed by the project "UPWR 2.0:international and interdisciplinary programme of development of Wrocław University of Environmental and Life Sciences" and cofinanced by the European Social Fund under the Operational Program Knowledge Education Development, under contract No. POWR.03.05.00-00Z062/18 of June 4, 2019.

\section{References}

[1] A. Aslam, M. Gajdács, C. S. Zin et al., "Evidence of the practice of self-medication with antibiotics among the lay public in low- and middle-income countries: a scoping review," Antibiotics, vol. 9, no. 9, p. 597, 2020.

[2] M. A. E. G. el-Sayed Ahmed, L. Zhong, C. Shen, Y. Yang, Y. Doi, and G. Tian, "Colistin and its role in the era of antibi- otic resistance: an extended review (2000-2019)," Emerging Microbes \& Infections, vol. 9, no. 1, pp. 868-885, 2020.

[3] B. M. Forde, H. M. Zowawi, P. N. A. Harris et al., "Discovery of mcr-1-Mediated colistin resistance in a highly Virulent Escherichia coli Lineage," mSphere, vol. 3, no. 5, article e00486, 2018.

[4] E. Elbediwi, Y. Li, N. Paudyal et al., "Global burden of colistin-resistant bacteria: mobilized colistin resistance genes study (1980-2018)," Microorganisms, vol. 7, no. 10, p. 461, 2019.

[5] Z. Ling, W. Yin, Z. Shen, Y. Wang, J. Shen, and T. R. Walsh, "Epidemiology of mobile colistin resistance genes $\mathrm{mcr}-1$ to mcr-9," The Journal of Antimicrobial Chemotherapy, vol. 75, no. 11, pp. 3087-3095, 2020.

[6] L. Poirel, A. Jayol, and P. Nordmann, "Polymyxins: antibacterial activity, susceptibility testing, and resistance mechanisms encoded by plasmids or chromosomes," Clinical Microbiology Reviews, vol. 30, no. 2, pp. 557-596, 2017.

[7] J. Kim, B. K. Hwang, H. Choi et al., "Characterization of $m c r-$ 1-harboring plasmids from pan drug-resistant Escherichia coli strains isolated from retail raw chicken in South Korea," Microorganisms, vol. 7, no. 9, p. 344, 2019.

[8] L. M. Lim, N. Ly, D. Anderson et al., "Resurgence of colistin: a review of resistance, toxicity, pharmacodynamics, and dosing," Pharmacotherapy, vol. 30, no. 12, pp. 1279-1291, 2010.

[9] S. Wang and J. Shen, "Active surveillance of the spread of mcr-1-positive.E coli," The Lancet Microbe, vol. 1, no. 1, pp. e4-e5, 2020.

[10] J. Li, R. L. Nation, J. D. Turnidge et al., "Colistin: the reemerging antibiotic for multidrug-resistant Gram-negative bacterial infections," The Lancet Infectious Diseases, vol. 6, no. 9, pp. 589-601, 2006.

[11] Y.-Y. Liu, Y. Wang, T. R. Walsh et al., "Emergence of plasmid-mediated colistin resistance mechanism MCR-1 in animals and human beings in China: a microbiological and molecular biological study," The Lancet Infectious Diseases, vol. 16, no. 2, pp. 161-168, 2016.

[12] A. Carattoli, "Resistance plasmid families in Enterobacteriaceae," Antimicrobial Agents and Chemotherapy, vol. 53, no. 6, pp. 2227-2238, 2009.

[13] S. J. Son, R. Huang, C. J. Squire, and I. K. H. Leung, "MCR-1: a promising target for structure-based design of inhibitors to tackle polymyxin resistance," Drug Discovery Today, vol. 24, no. 1, pp. 206-216, 2019.

[14] L. Lv, M. Wan, C. Wang et al., "Emergence of a plasmid encoded resistance-nodulation-division efflux pump conferring resistance to multiple drugs, including tigecycline, in Klebsiella pneumoniae," mBio, vol. 11, no. 2, article e02930, 2020.

[15] F. C. Cabello and H. P. Godfrey, "Aquaculture, exaptation, and the origin ofmcr-Positive colistin resistance," Antimicrobial Agents and Chemotherapy, vol. 62, no. 12, pp. e01903e01918, 2018.

[16] M. Gajdács, "The concept of an ideal antibiotic: implications for drug design,” Molecules, vol. 24, no. 5, p. 892, 2019.

[17] P. J. Collignon and S. A. McEwen, "One Health - its importance in helping to better control antimicrobial resistance," Tropical Medicine and Infectious Disease, vol. 4, no. 1, p. 22, 2019.

[18] C. Ng and K. Y. Gin, "Monitoring antimicrobial resistance dissemination in aquatic systems," Water, vol. 11, no. 1, p. 71, 2019. 
[19] M. U. Anyanwu, I. F. Jaja, and O. C. Nwobi, "Occurrence and characteristics of mobile colistin resistance ( $\mathrm{mcr}$ ) genecontaining isolates from the environment: a review," International Journal of Environmental Research and Public Health, vol. 17, no. 3, p. 1028, 2020.

[20] J. Hassan and I. I. Kassem, “Audacious hitchhikers: the role of travel and the international food trade in the global dissemination of mobile colistin-resistance ( $m c r$ ) genes," Antibiotics, vol. 9, no. 7, p. 370, 2020.

[21] S. Bontron, L. Poirel, and P. Nordmann, "Real-time PCR for detection of plasmid-mediated polymyxin resistance $(\mathrm{mcr}-1)$ from cultured bacteria and stools," The Journal of Antimicrobial Chemotherapy, vol. 71, no. 8, pp. 2318-2320, 2016.

[22] S. Chabou, T. Leangapichart, L. Okdah, S. le Page, L. Hadjadj, and J. M. Rolain, "Real-time quantitative PCR assay with Taqman ${ }^{\circledast}$ probe for rapid detection of $M C R-1$ plasmidmediated colistin resistance," New Microbes and New Infections, vol. 13, pp. 71-74, 2016.

[23] D. Gerber, "Colistin resistance in E. coli in broiler operations in South Africa," V-Tech Report, V-Tech Pty (Ltd), Johannesburg, 2016.

[24] R. Grami, W. Mansour, W. Mehri et al., "Impact of food animal trade on the spread of $m c r-1$-mediated colistin resistance, Tunisia, July 2015," Eurosurveillance, vol. 21, no. 8, 2016.

[25] H. O. Khalifa, A. M. Ahmed, A. F. Oreiby, A. M. Eid, T. Shimamoto, and T. Shimamoto, "Characterisation of the plasmid-mediated colistin resistance gene mcr-1 in Escherichia coli isolated from animals in Egypt," International Journal of Antimicrobial Agents, vol. 47, no. 5, pp. 413-414, 2016.

[26] A. O. Olaitan, S. Chabou, L. Okdah, S. Morand, and J.M. Rolain, "Dissemination of the $m c r-1$ colistin resistance gene," The Lancet Infectious Diseases, vol. 16, no. 2, p. 147, 2016.

[27] V. Perreten, C. Strauss, A. Collaud, and D. Gerber, "Colistin resistance gene $m c r-1$ in avian pathogenic Escherichia coli in South Africa," Antimicrobial Agents and Chemotherapy, vol. 60, no. 7, pp. 4414-4415, 2016.

[28] L. Hadjadj, T. Riziki, Y. Zhu, J. Li, S. Diene, and J.-M. Rolain, "Study of $\mathrm{mcr}$-1 gene-mediated colistin resistance in Enterobacteriaceae isolated from humans and animals in different countries," Genes (Basel), vol. 8, no. 12, p. 394, 2017.

[29] N. Lima Barbieri, D. W. Nielsen, Y. Wannemuehler et al., " $m c r-1$ identified in avian pathogenic Escherichia coli (APEC)," PLoS One, vol. 12, no. 3, article e0172997, 2017.

[30] L. L. Founou, R. C. Founou, M. Allam, A. Ismail, and S. Y. Essack, "Extended-spectrum beta-lactamase producing Escherichia coli harbouring $\mathrm{mcr}-1$ gene isolated from pigs in South Africa," South African Medical Journal, vol. 108, no. 10, pp. 796-797, 2018.

[31] A. A. Moawad, H. Hotzel, H. Neubauer et al., "Antimicrobial resistance in Enterobacteriaceae from healthy broilers in Egypt: emergence of colistin-resistant and extendedspectrum $\beta$-lactamase-producing Escherichia coli," Gut Pathogens, vol. 10, no. 1, p. 39, 2018.

[32] E. Maamar, C. A. Alonso, Z. Hamzaoui et al., "Emergence of plasmid-mediated colistin-resistance in CMY-2-producing Escherichia coli of lineage ST2197 in a Tunisian poultry farm," International Journal of Food Microbiology, vol. 269, pp. 60-63, 2018.

[33] S. Chabou, H. Leulmi, and J.-M. Rolain, "Emergence of $\mathrm{mcr}$ 1-mediated colistin resistance in _Escherichia coli_isolates from poultry in Algeria," Journal of Global Antimicrobial Resistance, vol. 16, pp. 115-116, 2019.

[34] B. Hassen, M. S. Abbassi, L. Ruiz-Ripa et al., "High prevalence of $m c r-1$ encoding colistin resistance and first identification of bla $a_{\mathrm{CTX}-\mathrm{M}-55}$ in ESBL/CMY-2-producing Escherichia coli isolated from chicken faeces and retail meat in Tunisia," International Journal of Food Microbiology, vol. 318, no. 2020, p. 108478, 2020.

[35] M. Saidani, L. Messadi, E. Sahmin et al., "ESBL- and mcr-1producing Escherichia coli in veal calves in Tunisia," Journal of Global Antimicrobial Resistance, vol. 19, pp. 104-105, 2019.

[36] M. Saidani, L. Messadi, J. Mefteh et al., "Various Inc-types plasmids and lineages of Escherichia coli and Klebsiella pneumoniae spreading $b l a_{\mathrm{CTX}-\mathrm{M}-15}, b l a_{\mathrm{CTX}-\mathrm{M}-1}$ and mor-1genes in camels in Tunisia," Journal of Global Antimicrobial Resistance, vol. 19, pp. 280-283, 2019.

[37] S. Dhaouadi, L. Soufi, A. Hamza et al., "Co-occurrence of mcr-1mediated colistin resistance and $\beta$-lactamase- encoding genes in multidrug-resistant Escherichia coli from broiler chickens with colibacillosis in Tunisia," Journal of Global Antimicrobial Resistance, vol. 22, no. 20, pp. 538-545, 2020.

[38] N. Rahmatallah, H. El Rhaffouli, A. Laraqui et al., "Detection of colistin encoding resistance genes MCR-1 in isolates recovered from broiler chickens in Morocco," Saudi Journal of Pathology and Microbiology, vol. 3, no. 12, pp. 520-521, 2018.

[39] M. Saidani, L. Messadi, A. Chaouechi et al., "High genetic diversity of Enterobacteriaceae clones and plasmids disseminating resistance to extended-spectrum cephalosporins and colistin in healthy chicken in Tunisia," Microbial Drug Resistance, vol. 25, no. 10, pp. 1507-1513, 2019.

[40] E. O. Ngbede, A. Poudel, A. Kalalah et al., "Identification of mobile colistin resistance genes $(m c r-1.1$, mcr-5 and mcr8.1) in Enterobacteriaceae and Alcaligenes faecalis of human and animal origin, Nigeria," International Journal of Antimicrobial Agents, vol. 56, no. 3, p. 106108, 2020.

[41] A. R. Manges, H. M. Geum, A. Guo, T. J. Edens, C. D. Fibke, and J. D. D. Pitout, "Global extraintestinal pathogenic Escherichia coli (ExPEC) lineages," Clinical Microbiology Reviews, vol. 32, no. 3, article e00135, 2019.

[42] J. Qiu, Z. Jiang, Z. Ju et al., "Molecular and phenotypic characteristics of Escherichia coli isolates from farmed minks in Zhucheng, China," BioMed Research International, vol. 2019, 12 pages, 2019.

[43] M. Mendelson, A. Brink, J. Gouws et al., "The One Health stewardship of colistin as an antibiotic of last resort for human health in South Africa," The Lancet Infectious Diseases, vol. 18, no. 9, pp. e288-e294, 2018.

[44] E. O. Ojo, E. Fabusoro, A. A. Majasan, and M. A. Dipeolu, "Antimicrobials in animal production: usage and practices among livestock farmers in Oyo and Kaduna States of Nigeria," Tropical Animal Health and Production, vol. 48, no. 1, pp. 189-197, 2016.

[45] P. Vounba, M. Rhouma, J. Arsenault, R. Bada Alambédji, P. Fravalo, and J. M. Fairbrother, "Prevalence of colistin resistance and $m c r-1 / m c r-2$ genes in extended-spectrum $\beta$-lactamase/AmpC-producing Escherichia coli isolated from chickens in Canada, Senegal and Vietnam," Journal of Global Antimicrobial Resistance, vol. 19, pp. 222-227, 2019.

[46] T. A. T. Gomes, W. P. Elias, I. C. A. Scaletsky et al., "Diarrheagenic Escherichia coli," Brazilian Journal of Microbiology, vol. 47, no. 47S, pp. 3-30, 2016. 
[47] O. O. Adebowale, F. A. Adeyemo, N. Bankole et al., "Farmers' perceptions and drivers of antimicrobial use and abuse in commercial pig production, Ogun State, Nigeria," International Journal of Environmental Research and Public Health, vol. 17, no. 10, p. 3579, 2020.

[48] M. Gajdács, A. Németh, M. Knausz et al., "Streptococcus suis: an underestimated emerging pathogen in Hungary?," Microorganisms, vol. 8, no. 9, p. 1292, 2020.

[49] T. Bandaw and T. Herago, "Review on abattoir waste management," Global Veterinaria, vol. 19, no. 2, pp. 517-524, 2017.

[50] B. Hassen, B. Saloua, M. S. Abbassi et al., "mcr -1 encoding colistin resistance in CTX-M-1/CTX-M-15- producing Escherichia coli isolates of bovine and caprine origins in Tunisia. First report of CTX-M-15-ST394/D E. coli from goats," Comparative Immunology, Microbiology and Infectious Diseases, vol. 67, p. 101366, 2019.

[51] M. Rhouma, S. Bessalah, I. Salhi, W. Thériault, J. M. Fairbrother, and P. Fravalo, "Screening for fecal presence of colistin-resistant Escherichia coli and mcr-1 and mcr-2 genes in camel-calves in southern Tunisia," Acta Veterinaria Scandinavica, vol. 60, no. 1, p. 35, 2018.

[52] M. Nüesch-Inderbinen, P. Kindle, M. Baschera et al., "Antimicrobial resistant and extended-spectrum ß-lactamase (ESBL) producing Escherichia coli isolated from fecal samples of African dromedary camels," Scientific African, vol. 7, article e00274, 2020.

[53] Z. I. Kimera, S. E. Mshana, M. M. Rweyemamu, L. E. G. Mboera, and M. I. N. Matee, "Antimicrobial use and resistance in food-producing animals and the environment: an African perspective," Antimicrobial Resistance and Infection Control, vol. 9, no. 1, p. 37, 2020.

[54] A. M. Hammad, M. Hoffmann, N. Gonzalez-Escalona et al., "Genomic features of colistin resistant Escherichia coli ST69 strain harboring $m c r-1$ on IncHI2 plasmid from raw milk cheese in Egypt," Infection, Genetics and Evolution, vol. 73, pp. 126-131, 2019.

[55] M. Sadek, L. Poirel, P. Nordmann, H. Nariya, T. Shimamoto, and T. Shimamoto, "Draft genome sequence of an $\mathrm{mcr}$ 1/IncI2-carrying multidrug-resistant Escherichia coli B1:ST101 isolated from meat and meat products in Egypt," Journal of Global Antimicrobial Resistance, vol. 20, pp. 4142, 2020.

[56] R. F. Sabala, M. Usui, Y. Tamura, S. M. Abd-Elghany, K. I. Sallam, and M. M. Elgazzar, "Prevalence of colistin-resistant Escherichia coli harbouring $\mathrm{mcr}$-1 in raw beef and ready-toeat beef products in Egypt," Food Control, vol. 119, p. 107436, 2021.

[57] M. Sadek, H. Nariya, T. Shimamoto et al., "First genomic characterization of $b l a_{\mathrm{VIM}-1}$ and $m c r-9$-coharbouring Enterobacter hormaechei isolated from food of animal origin," Pathogens, vol. 9, no. 9, p. 687, 2020.

[58] R. I. Manenzhe, H. J. Zar, M. P. Nicol, and M. Kaba, “The spread of carbapenemase-producing bacteria in Africa: a systematic review," The Journal of Antimicrobial Chemotherapy, vol. 70, no. 1, pp. 23-40, 2015.

[59] A. A. Moawad, H. Hotzel, O. Awad et al., "Occurrence of Salmonella enterica and Escherichia coli in raw chicken and beef meat in northern Egypt and dissemination of their antibiotic resistance markers," Gut Pathogens, vol. 9, no. 1, p. 57, 2017.

[60] T. Leangapichart, P. Gautret, P. Brouqui, Z. Mimish, D. Raoult, and J.-M. Rolain, “Acquisition of $m c r-1$ plasmid- mediated colistin resistance in Escherichia coli and Klebsiella pneumoniae during Hajj 2013 and 2014," Antimicrobial Agents and Chemotherapy, vol. 60, no. 11, pp. 6998-6999, 2016.

[61] M. Touati, L. Hadjadj, M. Berrazeg, S. Baron, and J. M. Rolain, "Emergence of Escherichia coli harbouring mcr-1 and mcr-3 genes in North West Algerian farmlands," Journal of Global Antimicrobial Resistance, vol. 21, pp. 132-137, 2020.

[62] A. Saran, "Disinfection in the dairy parlour," Revue Scientifque et Technique de l'OIE, vol. 14, no. 1, pp. 207-224, 1995.

[63] S. N. Garcia, B. I. Osburn, and J. S. Cullor, "A one health perspective on dairy production and dairy food safety," One Health, vol. 7, article 100086, 2019.

[64] J. M. Tiedje, W. Fang, C. M. Manaia et al., “Antibiotic resistance genes in the human-impacted environment: a One Health perspective," Pedosphere, vol. 29, no. 3, pp. 273-282, 2019.

[65] A. Igwaran, B. C. Iweriebor, and A. I. Okoh, "Molecular characterization and antimicrobial resistance pattern of Escherichia coli recovered from wastewater treatment plants in Eastern Cape South Africa," International Journal of Environmental Research and Public Health, vol. 15, no. 6, p. 1237, 2018.

[66] A. Gabriel, B. N. Tarcisse, M. Rachel, K. A. Christian, and O. N. N. Esther, "Study of colistin resistance encoded by the mcr-1 gene in community and clinical Pseudomonas in Brazzaville, Republic of Congo," Journal of Microbial \& Biochemical Technology, vol. 11, p. 422, 2019.

[67] T. Bachiri, R. Lalaoui, S. Bakour et al., "First report of the plasmid-mediated colistin resistance gene $\mathrm{mcr}-1$ in Escherichia coli ST405 isolated from wildlife in Bejaia, Algeria," Microbial Drug Resistance, vol. 24, no. 7, pp. 890-895, 2018.

[68] R. Drali, M. Berrazeg, L. L. Zidouni et al., "Emergence of $m c r-$ 1 plasmid-mediated colistin-resistant Escherichia coli isolates from seawater," Science of The Total Environment, vol. 642, pp. 90-94, 2018.

[69] Z. S. Ahmed, E. A. Elshafiee, H. S. Khalefa, M. Kadry, and D. A. Hamza, "Evidence of colistin resistance genes ( $m c r-1$ and $m c r-2$ ) in wild birds and its public health implication in Egypt," Antimicrobial Resistance \& Infection Control, vol. 8, no. 1, p. 197, 2019.

[70] C. Feng, P. Wen, H. Xu et al., "Emergence and comparative genomics analysis of Extended-Spectrum- $\beta$-Lactamase-Producing Escherichia coli carrying mcr-1 in fennec fox imported from Sudan to China," mSphere, vol. 4, no. 6, article e00732, 2019.

[71] B. Hassen, M. S. Abbassi, L. Ruiz-Ripa et al., "Genetic characterization of extended-spectrum $\beta$-lactamase-producingEnterobacteriaceaefrom biological industrial wastewater treatment plant in Tunisia with detection of the colistinresistancemcr-1 gene," FEMS Microbiology Ecology, vol. fiaa231, 2020.

[72] A. M. Salah, D. Najwa, M. Sihem, and H. Salah, "Current epidemiology of non-beta-lactam antibiotics-resistance in Escherichia coli from animal origins in Tunisia: a paradigm of multidrug resistance," Archives of Clinical Microbiology, vol. 7, no. 5, p. 29, 2016.

[73] Y. Gao, C. Lu, D. Shen et al., "Elimination of the risks of colistin resistance gene $(\mathrm{mcr}-1)$ in livestock manure during composting," Environment International, vol. 126, pp. 61-68, 2019. 
[74] N. Fouz, K. N. A. Pangesti, M. Yasir et al., "The contribution of wastewater to the transmission of antimicrobial resistance in the environment: implications of mass gathering settings," Tropical Medicine and Infectious Disease, vol. 5, no. 1, p. 33, 2020.

[75] M. Berrazeg, A. Deriet, S. C. J. De Keersmaecker et al., "Whole-genome sequencing of multidrug-resistant Escherichia coli strains harboring the $m c r-1$ gene, isolated from seawater of the Algiers coast in Algeria," Microbiology Resource Announcements, vol. 8, no. 34, article e00638, 2019.

[76] M. Berrazeg, L. Hadjadj, A. Ayad, M. Drissi, and J.-M. Rolain, "First detected human case in Algeria of $m c r-1$ plasmidmediated colistin resistance in a 2011 Escherichia coli isolate," Antimicrobial Agents and Chemotherapy, vol. 60, no. 11, pp. 6996-6997, 2016.

[77] B. Yanat, J. Machuca, R. D. Yahia, A. Touati, Á. Pascual, and J. M. Rodríguez-Martínez, "First report of the plasmidmediated colistin resistance gene $m c r-1$ in a clinical Escherichia coli isolate in Algeria," International Journal of Antimicrobial Agents, vol. 48, no. 6, pp. 760-761, 2016.

[78] N. Adam and H. N. Altayb, "First report of colistin resistance (MCR-1) gene in Escherichia coli and Klebsiella pneumoniae isolated from clinical specimens in Khartoum," Journal of Proteomics and Bioinformatics, vol. 10, p. 11, 2017.

[79] A. Zakaria, M. Rhmtallah, Z. M. Abdo, M. F. Ismail, A. H. Ali, and M. N. Mohammed Hamad, "Molecular detection of colistin resistance gene $m c r-1$ in Gramnegative rods isolated from hospitalized patients in Khartoum State," Saudi Journal of Pathology and Microbiology, vol. 5, no. 8, pp. 380-384, 2020.

[80] C. Kyany'a and L. Musila, "Colistin resistance Genemcr-8in a high-risk sequence type $15 \mathrm{Klebsiella}$ pneumoniaeIsolate from Kenya," Microbiology Resource Announcements, vol. 9, no. 39, article e00783, 2020.

[81] T. Büdel, E. Kuenzli, M. Clément et al., "Polyclonal gut colonization with extended-spectrum cephalosporin- and/or colistin-resistant Enterobacteriaceae: a normal status for hotel employees on the island of Zanzibar, Tanzania," Journal of Antimicrobial Chemotherapy, vol. 74, no. 10, pp. 28802890, 2019.

[82] K. Otokunefor, E. Tamunokuro, and A. Amadi, "Molecular detection of mobilized colistin resistance ( $\mathrm{mcr}-1)$ gene in Escherichia coli isolates from Port Harcourt, Nigeria," Journal of Applied Sciences and Environmental Management, vol. 23, no. 3, pp. 401-405, 2019.

[83] J. Coetzee, C. Corcoran, E. Prentice et al., "Emergence of plasmid-mediated colistin resistance (MCR-1) among Escherichia coli isolated from South African patients," South African Medical Journal, vol. 106, no. 5, pp. 449-450, 2016.

[84] L. Poirel, N. Kieffer, A. Brink, J. Coetze, A. Jayol, and P. Nordmann, "Genetic features of MCR-1-producing colistin-resistant Escherichia coli isolates in South Africa," Antimicrobial Agents and Chemotherapy, vol. 60, no. 7, pp. 4394-4397, 2016.

[85] K. Strydom, M. Lowings, C. Kingsburgh et al., "Emergence of $m c r-1$ in Escherichia coli isolates at a tertiary referral laboratory in Pretoria, South Africa," 2017, https://www.escmid .org/escmid_publications/escmid_elibrary/material/?mid= 51549.

[86] M. Newton-Foot, Y. Snyman, M. R. B. Maloba, and A. C. Whitelaw, "Plasmid-mediated $m c r-1$ colistin resistance in Escherichia coli and Klebsiella spp. clinical isolates from the
Western Cape region of South Africa," Antimicrobial Resistance \& Infection Control, vol. 6, no. 1, p. 78, 2017.

[87] J. Osei Sekyere, N. E. Maningi, L. Modipane, and N. M. Mbelle, "Emergence of mcr-9.1 in extended-spectrum- $\beta$-lactamase-producing Clinical Enterobacteriaceae in Pretoria, South Africa: global evolutionary phylogenomics, resistome, and mobilome," mSystems, vol. 5, no. 3, article e00148, 2020.

[88] N. Kieffer, G. Royer, J. W. Decousser et al., " $m c r-9$, an inducible gene encoding an acquired phosphoethanolamine transferase in Escherichia coli, and its origin," Antimicrobial Agents and Chemotherapy, vol. 63, no. 9, 2019.

[89] M. el Sayed Zaki, N. Abou ElKheir, and M. Mofreh, "Molecular study of colistin resistant clinical isolates of Enterobacteriaceae species," Journal of Clinical and Molecular Medicine, vol. 1, no. 1, pp. 1-4, 2018.

[90] R. A. Rabie and A. L. Abdallah, "Plasmid mediated colistin resistant genes mcr-1 and mcr-2 among Escherichia coli and Klebsiella pneumoniae isolates at Zagazig University hospitals, Egypt," Egyptian Journal of Medical Microbiology, vol. 29, no. 1, pp. 61-66, 2019.

[91] S. S. Elnahriry, H. O. Khalifa, A. M. Soliman et al., "Emergence of plasmid-mediated colistin resistance gene mcr-1 in a clinical Escherichia coli isolate from Egypt," Antimicrobial Agents and Chemotherapy, vol. 60, no. 5, pp. 3249-3250, 2016.

[92] R. M. A. El-Baky, S. M. Masoud, D. S. Mohamed et al., "Prevalence and some possible mechanisms of colistin resistance among multidrug-resistant and extensively drug-resistant Pseudomonas aeruginosa," Infection and Drug Resistance, vol. 13, pp. 323-332, 2020.

[93] M. Shabban, N. A. E. Fahim, K. Montasser, and N. M. A. el Magd, "Resistance to colistin mediated by mcr-1 among multidrug resistant Gram negative pathogens at a tertiary care hospital, Egypt," Journal of Pure and Applied Microbiology, vol. 14, no. 2, pp. 1125-1132, 2020.

[94] A. M. Soliman, F. Maruyama, H. O. Zarad et al., "Emergence of a multidrug-resistant Enterobacter hormaechei clinical isolate from Egypt co-harboring $m c r-9$ and $b l a_{\mathrm{VIM}-4}$," Microorganisms, vol. 8, no. 4, p. 595, 2020.

[95] M. M. Zafer, H. A. El-Mahallawy, A. Abdulhak, M. A. Amin, M. H. Al-Agamy, and H. H. Radwan, "Emergence of colistin resistance in multidrug-resistant Klebsiella pneumoniae and Escherichia coli strains isolated from cancer patients," Annals of Clinical Microbiology and Antimicrobials, vol. 18, no. 1, p. 40, 2019.

[96] L. Z. Nabti, F. Sahli, L. Hadjadj et al., "Autochthonous case of mobile colistin resistance gene mcr-1 from a uropathogenic Escherichia coli isolate in Sétif Hospital, Algeria," Journal of Global Antimicrobial Resistance, vol. 19, pp. 356-357, 2019.

[97] L. Z. Nabti, F. Sahli, E. P. Ngaiganam et al., "Development of real-time PCR assay allowed describing the first clinical Klebsiella pneumoniae isolate harboring plasmid-mediated colistin resistance mcr-8 gene in Algeria," Journal of Global Antimicrobial Resistance, vol. 20, pp. 266-271, 2020.

[98] D. M. P. De Oliveira, B. M. Forde, T. J. Kidd et al., "Antimicrobial resistance in ESKAPE pathogens," Clinical Microbiology Reviews, vol. 33, no. 3, article e00181, 2020.

[99] C. Ayoub Moubareck and D. Hammoudi Halat, "Insights into Acinetobacter baumannii: a review of microbiological, virulence, and resistance traits in a threatening nosocomial pathogen," Antibiotics, vol. 9, no. 3, p. 119, 2020. 
[100] S. Baron, L. Bardet, G. Dubourg, M. Fichaux, and J. M. Rolain, "mcr-1 plasmid-mediated colistin resistance gene detection in an Enterobacter cloacae clinical isolate in France," Journal of Global Antimicrobial Resistance, vol. 10, pp. 35-36, 2017.

[101] O. Henig, L. J. Rojas, M. A. Bachman et al., "Identification of four patients with colistin-resistant Escherichia coli containing the mobile colistin resistance mcr-1 gene from a single health system in Michigan," Infection Control \& Hospital Epidemiology, vol. 40, no. 9, pp. 1059-1062, 2019.

[102] M. Doumith, G. Godbole, P. Ashton et al., "Detection of the plasmid-mediated mcr-1 gene conferring colistin resistance in human and food isolates of Salmonella enterica and Escherichia coli in England and Wales," The Journal of Antimicrobial Chemotherapy, vol. 71, no. 8, pp. 2300-2305, 2016.

[103] Z. Shen, Y. Wang, Y. Shen, J. Shen, and C. Wu, "Early emergence of mcr-1 in Escherichia coli from food-producing animals," The Lancet Infectious Diseases, vol. 16, no. 3, p. 293, 2016.

[104] F. El Garch, M. Sauget, D. Hocquet, D. LeChaudee, F. Woehrle, and X. Bertrand, " $m c r-1$ is borne by highly diverse Escherichia coli isolates since 2004 in foodproducing animals in Europe," Clinical Microbiology and Infection, vol. 23, no. 1, pp. 51.e1-51.e4, 2017.

[105] M. Gajdács, M. Ábrók, A. Lázár et al., "Detection of VIM, NDM and OXA-48 producing carbapenem resistant Enterobacterales among clinical isolates in Southern Hungary," Acta Microbiologica et Immunologica Hungarica, 2020. 